\title{
برنامج تثقيفي للتوعية بمفهوم المواطنة الرقمية لدى الصهم والعاديين: دراسة مقارنة
}

\author{
سحرزيدان زيان \\ أستاذ الصحة النفسية والتربية الخاصة المشارك- قسم التربية الخاصية ومشرفة برنامج الصمر جامعانة تبوك- السعودية
}

Sah_zed@hotmail.com

تهدف الدراسة الحالية إلى تقديم برنامج تثقيفي للتوعية بمفهوم المواطنة الرقمية لدي الصمم والعاديين: دراسة مقارنة، وقد اشتملت العينة

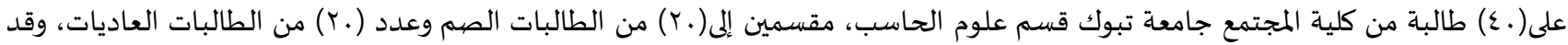

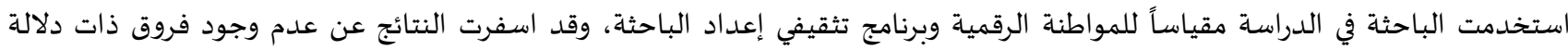

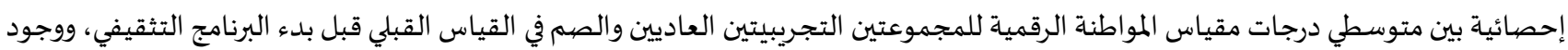

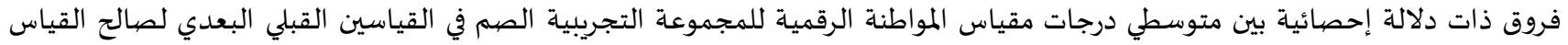

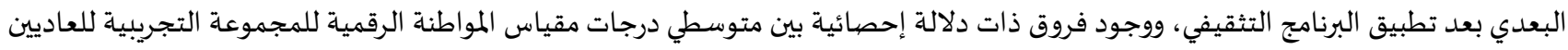

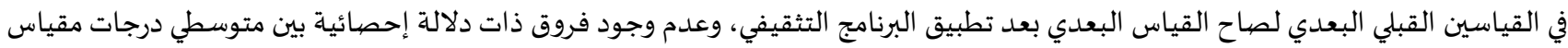

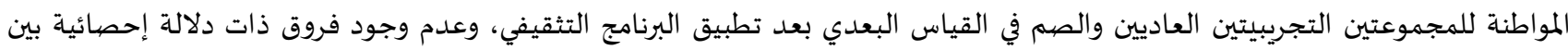

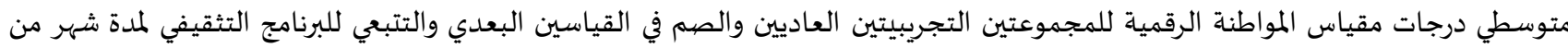
تطبيق البرنامج.

الكلمات المفتاحية: برنامج تثقيفي؛ المواطنة الرقمية؛ الصم. () (1)

المقدمة:

في ظلل العصر الرقهي وانتشار التكنولوجيا، اتخذت المواطنة أشكالاً وصوراً جديدة، أخذت فيه حقوق وواجبات المواطن شكلاً جديداً يتفق مع

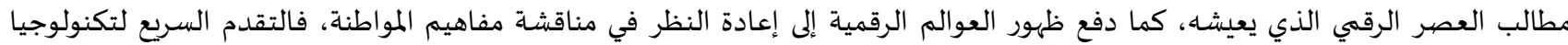

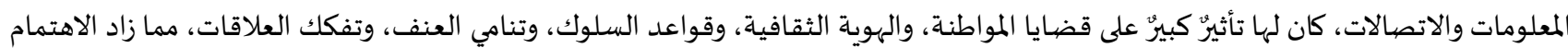

بموضوع المواطنة على مستوى عالمي. (Mossberg, Tolbert \& McNeal; 2011).

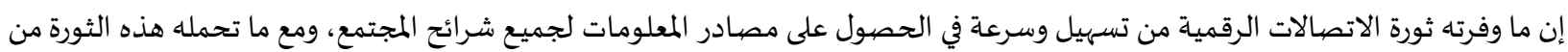

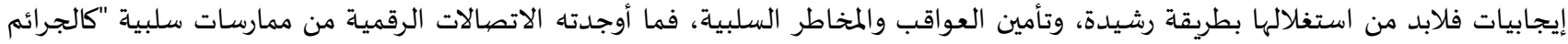

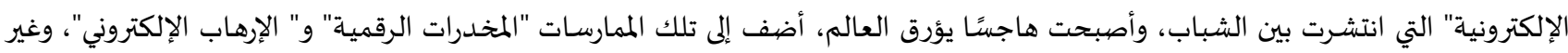

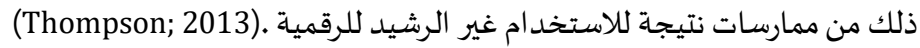

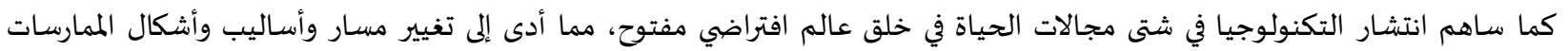

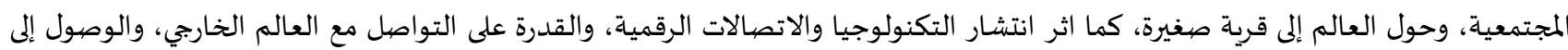

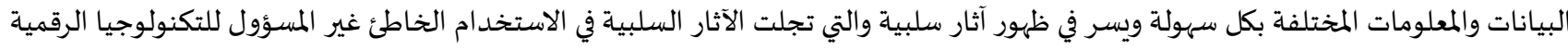

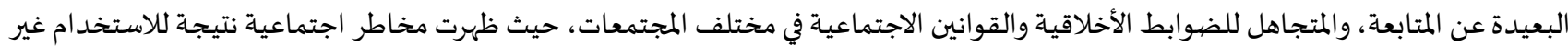

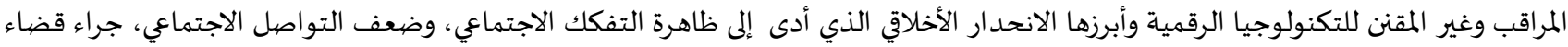


وإزاء ما يموج به العصر الحالي من تغييرات جذرية في المفاهيم والرؤى والمضامين، وما يشهده من انفجار معرفي وتطور تكنولوبي وثورة رقمية،

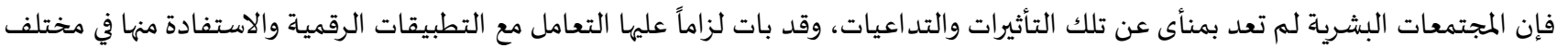

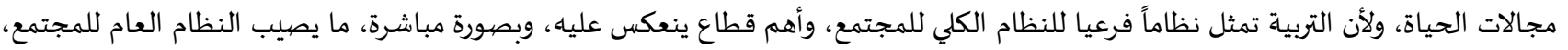

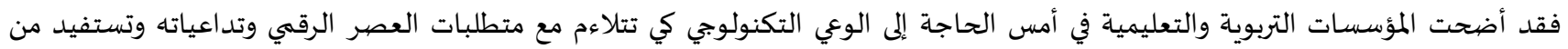

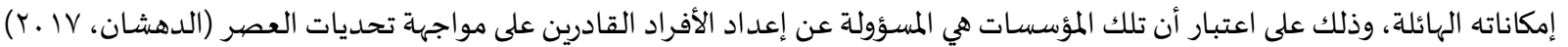

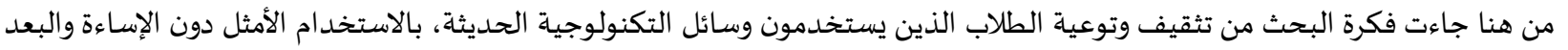

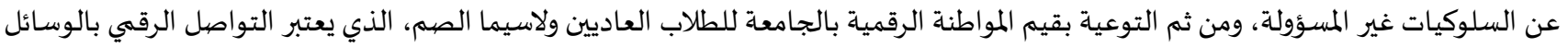

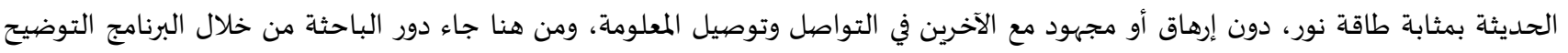
لمفاهيم المواطنة الرقمية وتعزيز الاستفادة القصوى للتحول الرقمي في التربية والتعامل، في ظل انتشار الجرائمائم الرقمية وانتشار العديد التعايد من الأفكار

إن الحاجة إلى مواكبة التغيرات والتحديات التي فرضتها متطلبات المجتمع الحديثة من ثورة تكنولوجية حديثة، شَكََّّة ذلك مسئولية على التعليم

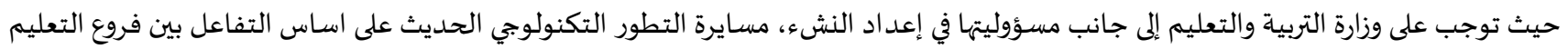

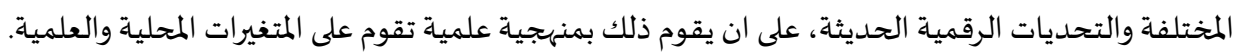

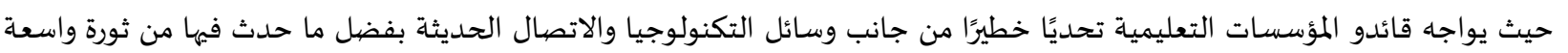

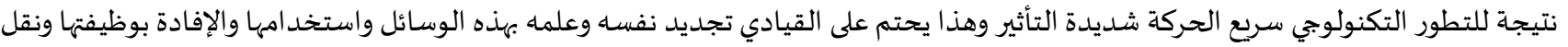

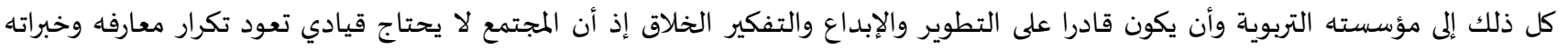

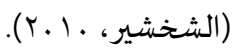

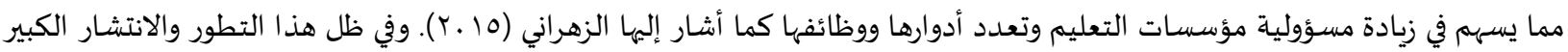

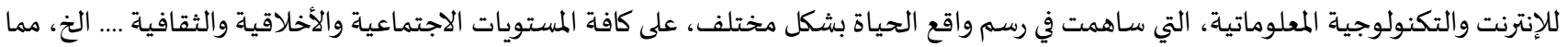

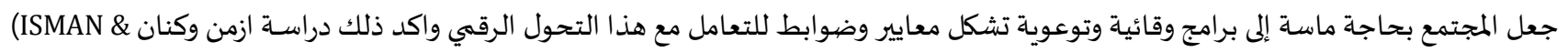
(Canan, 2013)

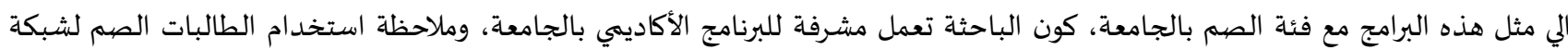

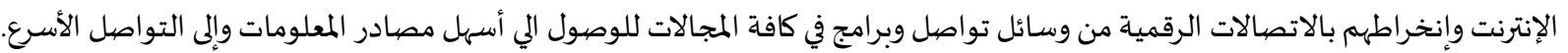

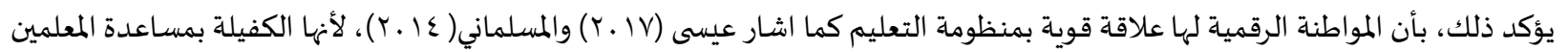

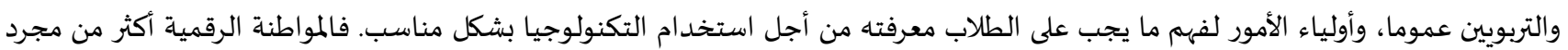

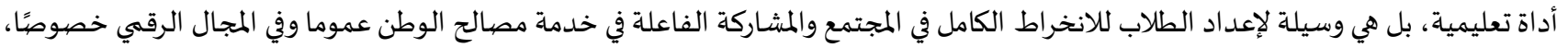

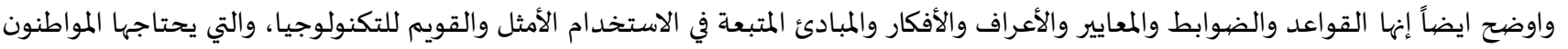

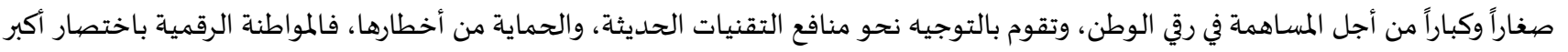

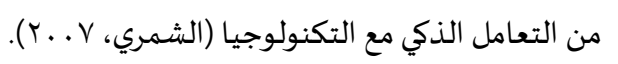

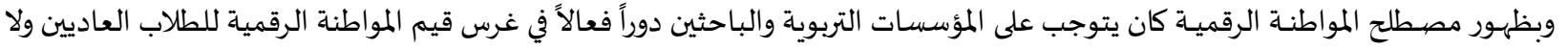

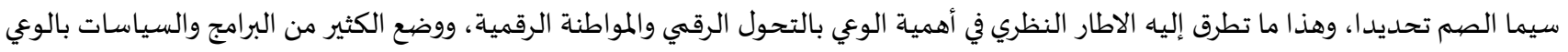

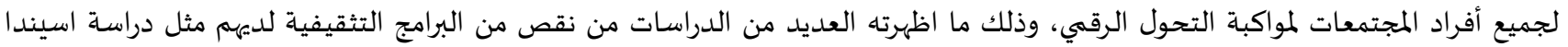
(Asunda, 2012)

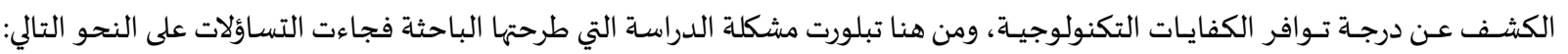

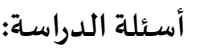

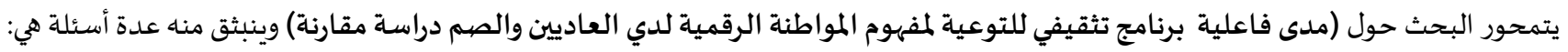

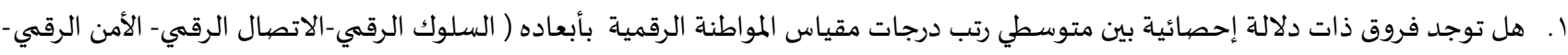

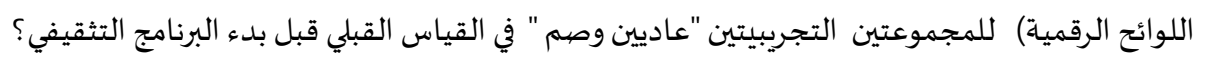


r. هل توجد فروق ذات دلالة إحصائية بين متوسطي رتب درجات مقياس المواطنة الرقمية بأبعاده ( السلوك الرقمي-الاتصال الرقمي- الأمن الرقي-

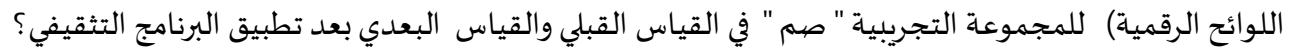

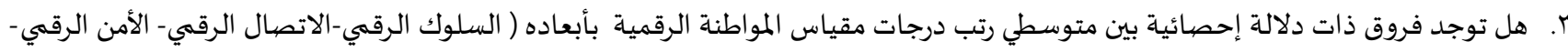

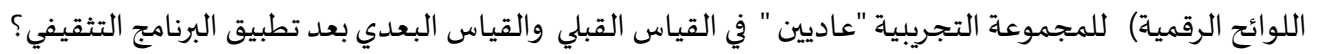

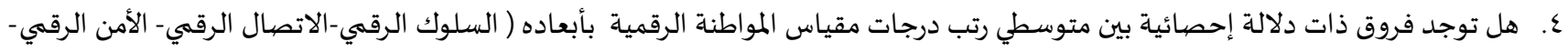

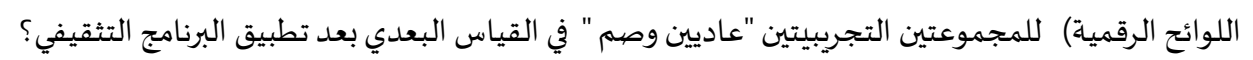

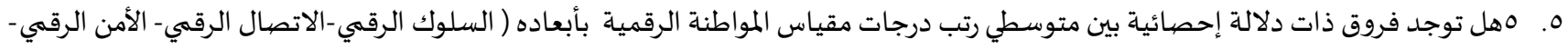

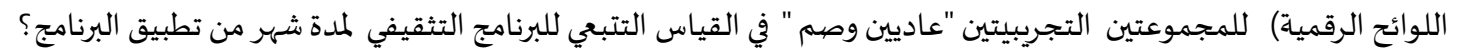
7.

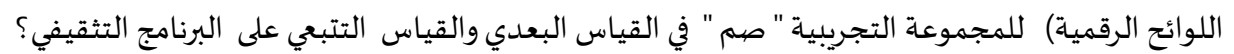

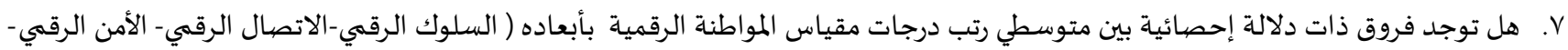

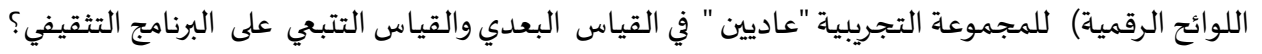

أهداف الدراسـة: تهدف الدراسـة الحالية إلى: ا. الوقوف على مفهوم المواطنة الرقمية وأبعادها المختلفة.

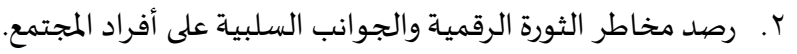

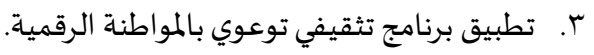
ع. معرفة الفروق بين مفهوم المواطنة الرقمية بين العاديين والصهم من طالبات الجامعة قبل وبعد البرنامج التثقيفي.

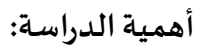

تكمن أهمية الدراسـة فيما يلي: من الناحية النظرية:

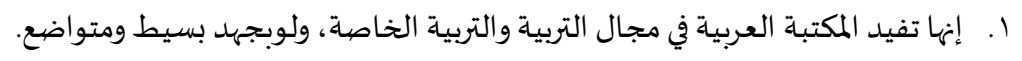

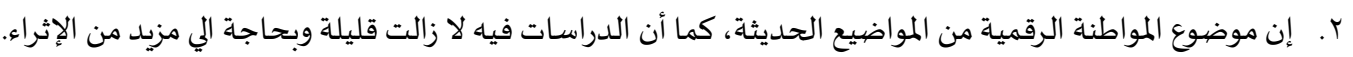

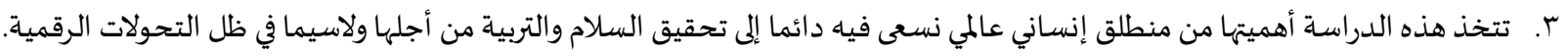

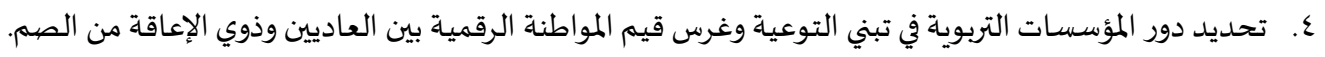

من الناحية التطبيقية:

ا. ت تأتي الدراسة مع التوجهات العالمية نحو التكنولوجيا الرقمية وتقدم مدخلا تربويا للمساهمة في مفهوم المواطنة الرقمية

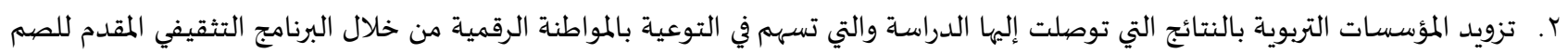
والعاديين. r. تأتي الأهمية التطبيقية للدراسة في البرنامج التثقيفي في امتلاك مهارات الممارسة الفعالة والمناسبة في استخدامات العالم الرقمي بألياته المختلفة. ع. تصميم مقياس لبعض أبعاد المواطنة الرقمياة.

محددات الدراسـة: قُسمَت حدود البحث إلى ثلاثة أقسام، وهي: • الحدود الموضيوعية: وتتحدد بتقديم برنامج تثقيفي للطالبات الصهم والعاديين، من خلال مقياس المواطنة الرقمية وذلك وفق أربعة أبعاد ( السلوك الرقمي-الاتصال الرقمي- الامن الرقمي- اللوائح الرقمية).

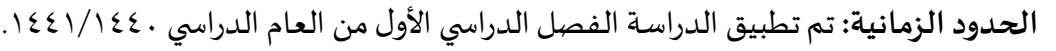
• الحدود المكانية: قسم علوم الحاسب كلية المجتمع جامعة تبوك. الحدود البشرية: طالبات قسم علوم الحاسب وعددهن ( .ع) طالبة بكلية المجتمع بجامعة تبوك. 


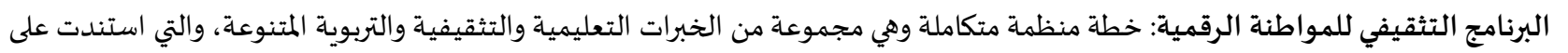

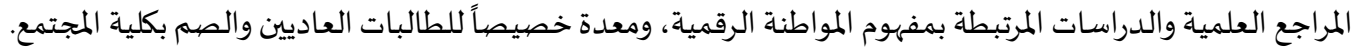

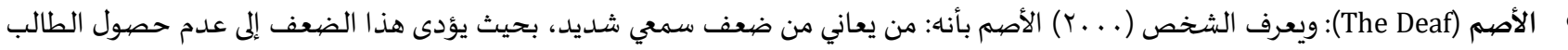

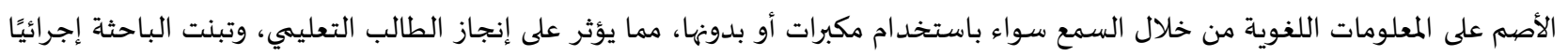

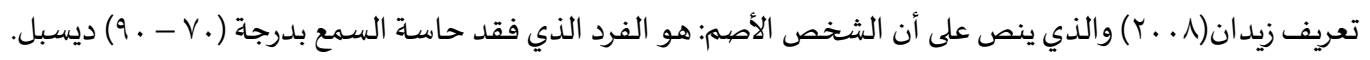

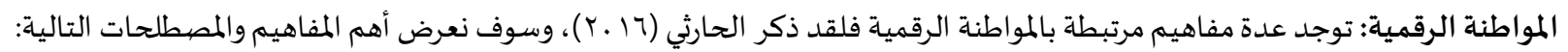
1 إمواطنة. r.

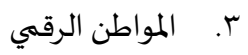

المواطنة: المواطنة لغويًا: مشتقة من وطن، والوطن بحسب كتاب لسان العرب "لابن منظور" المنزل الذي تقيم فيه، وهو موطن الإنسان ومحله، ووطن

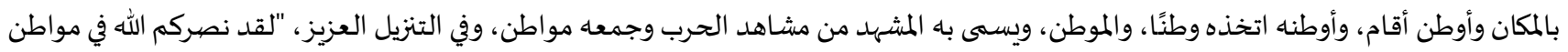

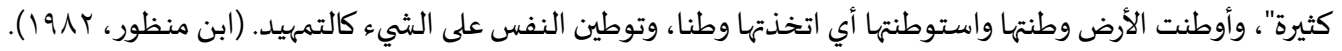

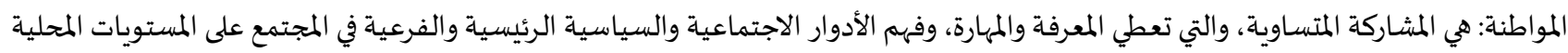
والوطنية والقومية والإنسانية، كما تؤهلهم للمسؤولية الوطنية، وتعرفهم بحقوقهم وواجباتهم الأخلاقية والسلوكية، وتجعل منهم مواطنين أكثر

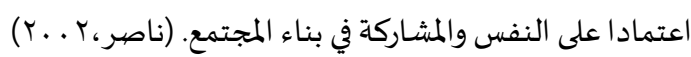

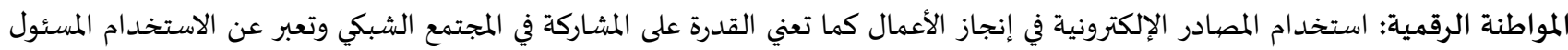

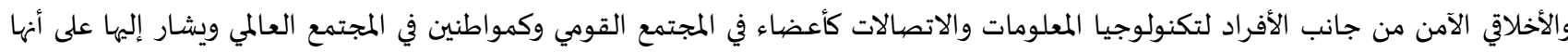

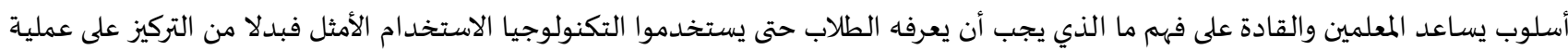

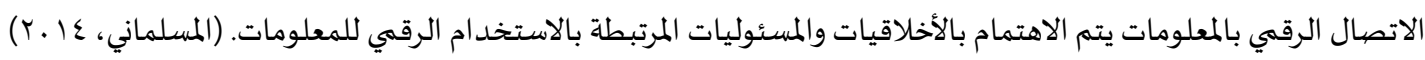

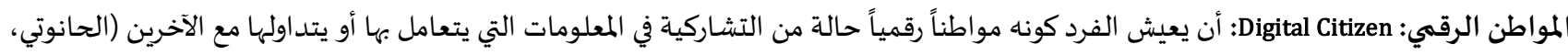

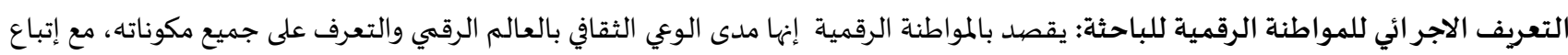

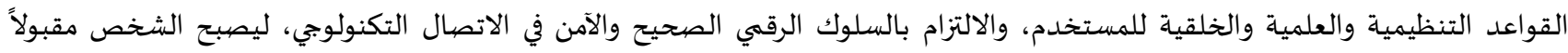
اجتماعياً في تفاعله الرقيه.

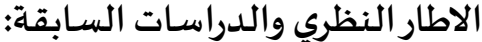

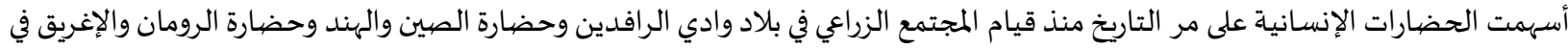

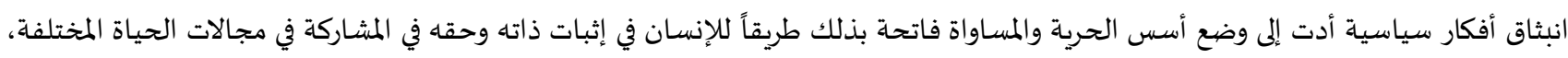

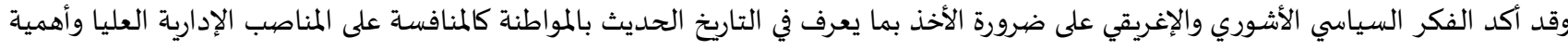

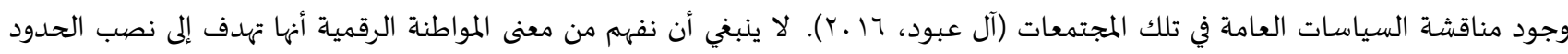

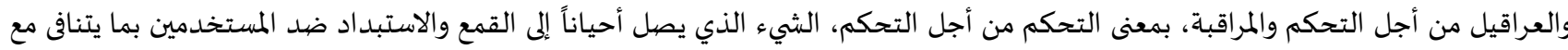

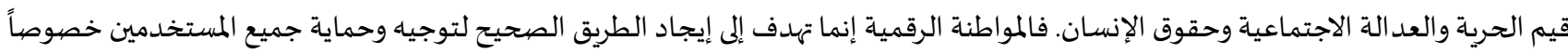

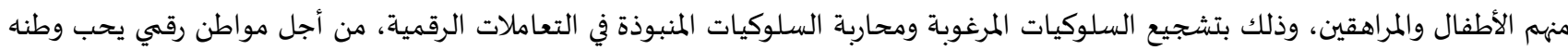

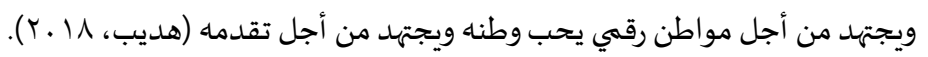

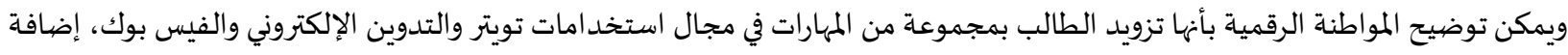

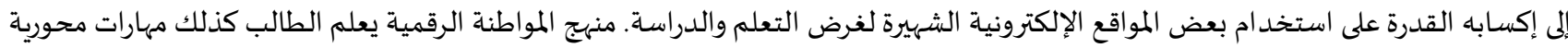

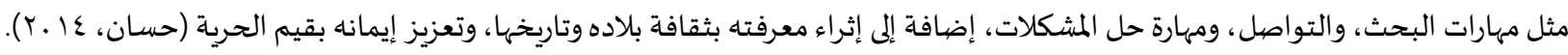

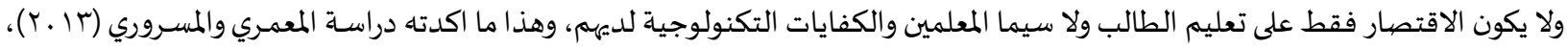

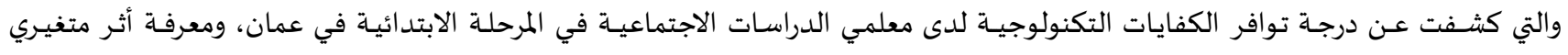

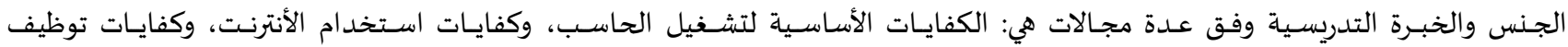




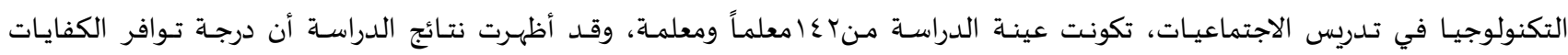

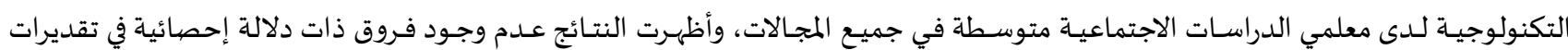

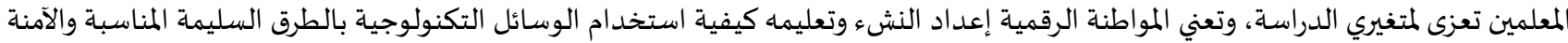

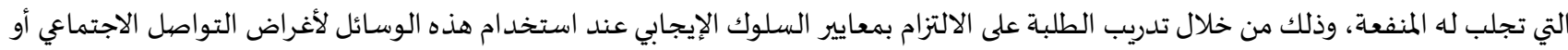

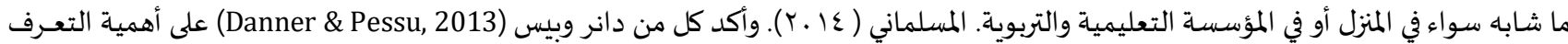

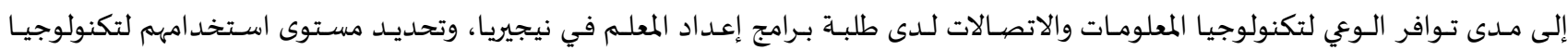

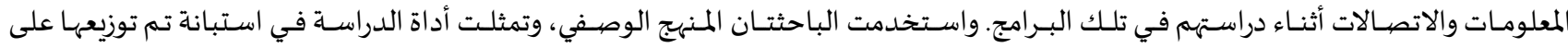

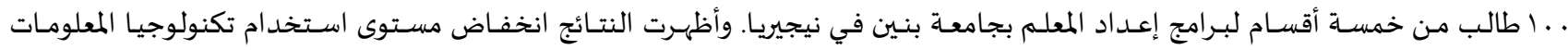

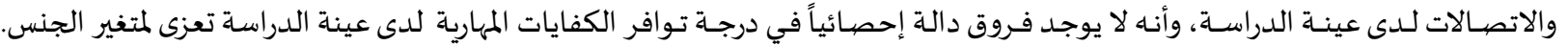

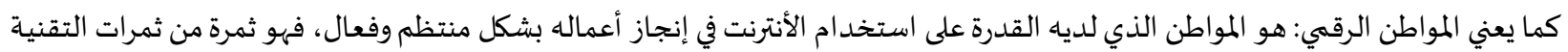

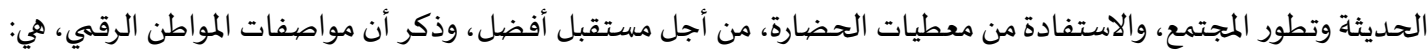

$$
\text { يلتزم بالأمانة الفكرية. }
$$

يحترم الثقافات والمجتمعات في البيئة الافتراضية.

يحافظ على المعلومات الشخصية.

يدير الوقت الذي يقضيه في استخدام التكنولوجيا.

يحمي نفساه من المعتقدات الفاسدة التي تنتشر عبر الوسائط.

يقف ضد التسلط عبر الأنترنت.(الأسمري، 10 . ب)

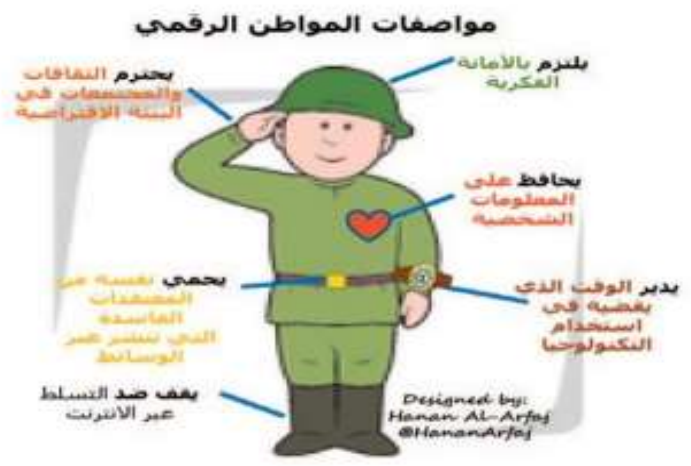

شكل رقم (1): مواصفات المواطن الرقي

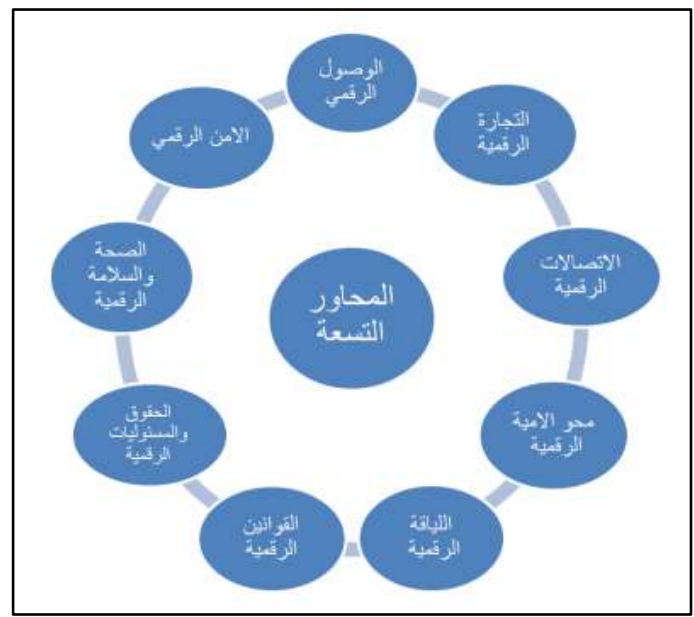

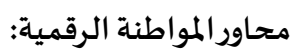

شكل رقم (r): محاور المواطنة الرقمية

مصدر: (http://blog.naseej.com/2013/07/11, 9/1/2020) 
ويظهر من الشكل السابق أن محاور المواطنة الرقمياة، تعني:

الوصول الرقهي: المشاركة الإلكترونية الكاملة في المجتمع.

التجارة الإلكترونية: بيع وشراء البضائع إلكترونياً.

الاتصالات الرقمية: التبادل الإلكتروني للمعلومات.

محو الأمية الرقمية: عملية تعليم وتعلم التكنولوجيا واستخدام أدواتها.

اللياقة الرقمياة: المعايير الرقمية للسلوك والإجراءات

القوانين الرقمية: المسئولية الرقمية على الأعمال والأفعال.

الحقوق والمسؤوليات الرقمية: الحريات التي يتمتع بها الجميع في العالم الرقمي.

الصحة والسلامة الرقمية: الصحة النفسية والبدنية في عالم التكنولوجيا الرقمية.

الأمن الرقهي (الحماية الذاتية): إجراءات ضمان الوقاية والحماية الإلكترونية.

أبعاد المواطنة الرقمية وعناصرها:

إذا كانت المواطنة الرقمية يمكن تعريفها على أهها تلك المعايير وقواعد السلوك المناسبة والمقبولة والمتعلقة باستخدام التكنولوجيا، فقد اتفق

الباحثون وكثير من المنظمات المرتبطة بذلك الميدان على تسعة أبعاد عامة تشكل المواطنة الرقمية، وهي: ا. الوصول الرقهي: يعد الوصول الرقهي من المواضيع الهامة والتي تتطرق إلهها العديد من الباحثين ويمكن تعريفها بأهها السماح بالمشاركة الكاملة في

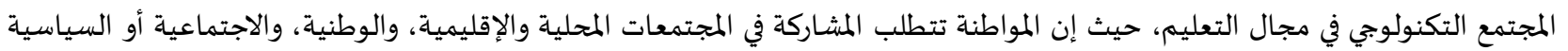
لكي يكون لأعضاء المجتمع قيمة ومعنى، ومن دون المشاركة يصبح المجتمع غير موجود، حيث يضطلع المجتمع بدوره في إعداد الشباب للمشاركة في

هذه المجتمعات (Ohler, 2011).

r. التجارة الإلكترونية: إن مستخدمي التكنولوجيا ينبني أن يعوا أن عمليتي البيع والشراء للبضائع والمستلزمات تتم بشكل واسع وسريع عبر الوسائل

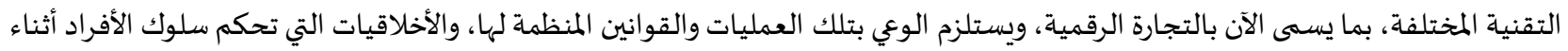

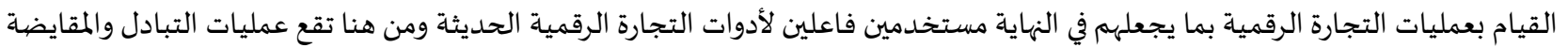
بصورة قانونية ومشروعة في نفس الوقت، لكن لابد أن يكون كل من البائع والمشتري على وعي بالقضايا المتعلقة بهذه العمليات. فقد أصبح الاتجاه

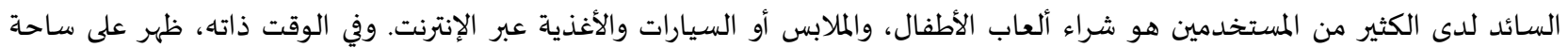
المعاملات قدراً مماثلاً من المنتجات والخدمات التي تتعارض مع قوانين ولوائح بعض الدول والتي تضمى عدداً من الأنشطة من بينها: تنزيل البرمجيات

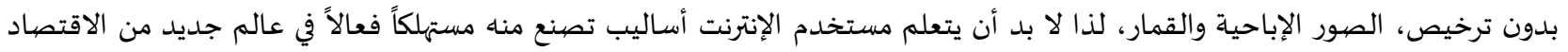

r. الاتصالات الرقمية: يعمل الاتصال عبر الإنترنت على توسيع شبكة علاقات الفرد الاجتماعية مع الآخرين على المستوى المحلي والإقليمي والدولي،

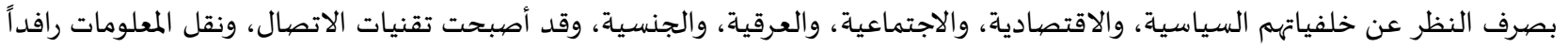

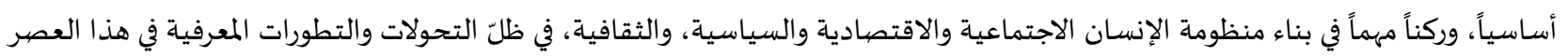

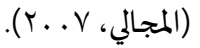

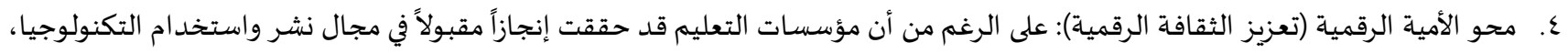

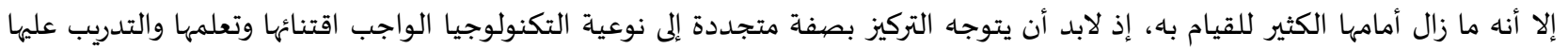

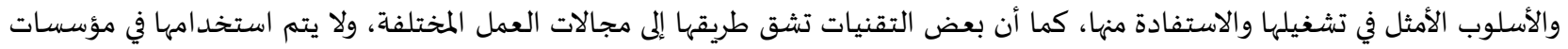

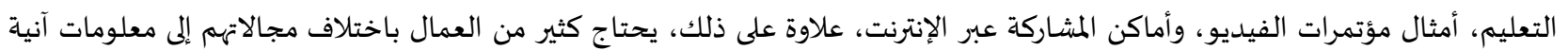
وفورية. وتتطلب هذه العملية مهارات بحث ومعالجة معقدة من بينها محو الأمية المعلوماتية ولذا لا بد أن يتعلم الدارسون كيف يتعلمون في ظل مهل مجتمع رقهي، وبعبارة أخرى لا بد من تدريب الدارسين على أن يتعلموا أي شيء، في أي وقت، في أي مكان. وتعد مجالات الأعمال والطب من من أبرز

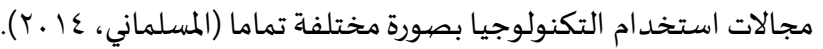
تعقيباً على ذلك اصبحنا الان في عصر محو الامية الرقهي، وهذا المفهوم التي تسعى إليه المجتمعات لتحقق للرقي والتقدم بين الدول المتقدمة تكنولوجيا، وعندما يصبح محو الامية الرقمية يشمل فئة الصهم ونمكنهم من استخدام الاتصالات الرقمية الحديثة في حياتهم اليومية، كما اشارت المات

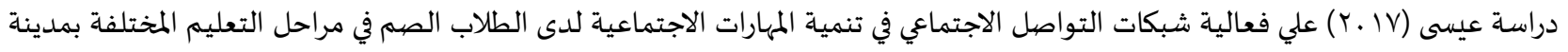
جدة، واتبع البحث المنهج الوصفي التحليلي، حيث تتم مراجعة الأدبيات والدراسات السابقة واستخلاص قائمة بالمهارات الاجتماعية للصهم مرئم ومنظومة شبكات التواصل، وتم إعداد استبانة تقييمية لاستخدام الطلاب الصم شبكات التواصل الاجتماعي. وأعد مقياس تقييمي للمهارات 
الاجتماعية في تنمية مفهوم الذات وتكوين الصدقات، الاتصال والتواصل. والعلاقات الشخصية والانتماء والمواطنة من وجهة نظر الطلاب الصيم التي يمكن أن تسهم شبكات التواصل الاجتماعي في تنميتها لدى الطلاب الصهم. وتكونت عينة البحث من (.ץ) فرداً من الطلاب الصهم. وتم رصهد

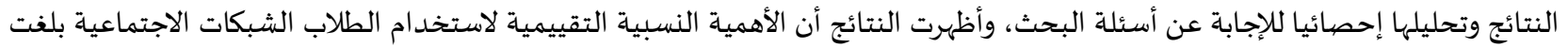

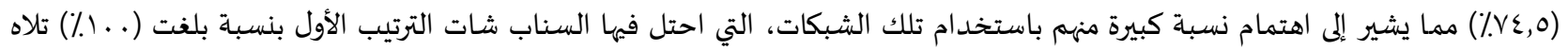

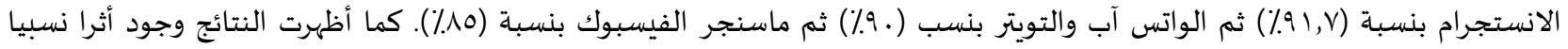

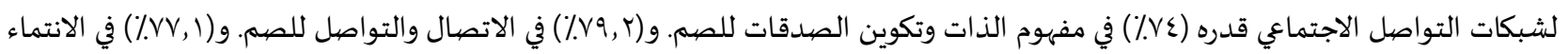
والمواطنة والعلاقات الشخصية للصهم. وتم صياغة أهم التوصيات التطبيقية للمساهمة في توظيف شبكات التواصل الاجتماعي في تحسين نوعية حياة الطلاب الصهم. ه. اللياقة الرقمية (الإتيكيت الرقهي): تهتم المواطنة الرقمية بنشر "ثقافة الإتيكيت" الرقمي بين الأفراد وتدريبهم ليكونوا مسؤولين في ظل مجتمع رقهي جديد، ليتصرفوا بتحضر، مراعين القيم والمبادئ ومعايير السلوك الحسن. وغالباً ما يرى مستخدمو التكنولوجيا هذا المجال بوصفيه أكثر بـائر

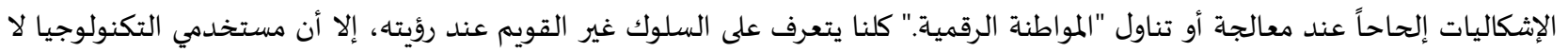

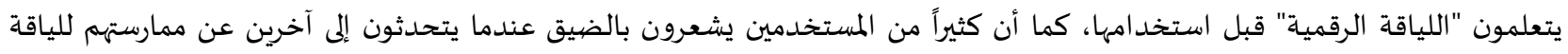

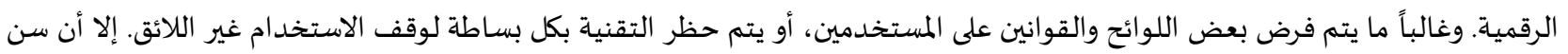

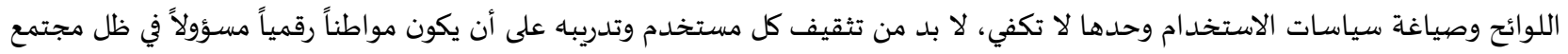

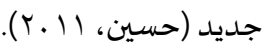
7 ال القوانين الرقمية (المسؤولية الاجتماعية على الأعمال والأفعال): وهو الذي يقوم بمعالجة مسألة الأخلاقيات المتبعة داخل مجتمع التكنولوجيا،

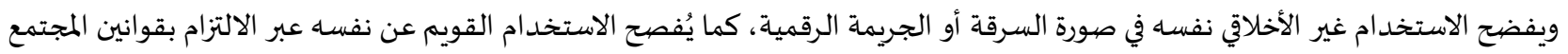
الرقهي، ولا بد أن يعرف المستخدمون أن سرقة أو إهدار ممتلكات الآخرين، أو أعمالهه أو هويتهم عبر الانترنت يعد جريمة أمام القانون، ومن هنا

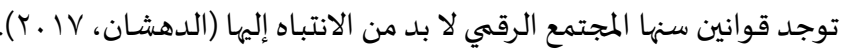

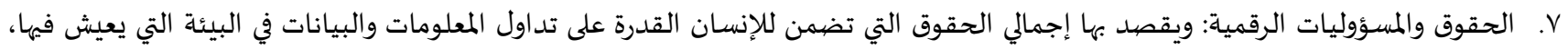

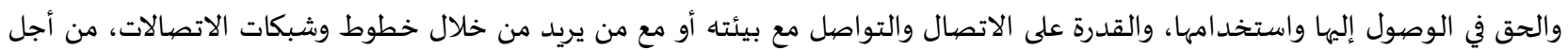

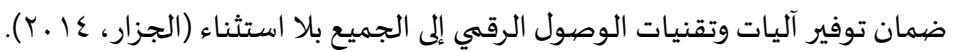

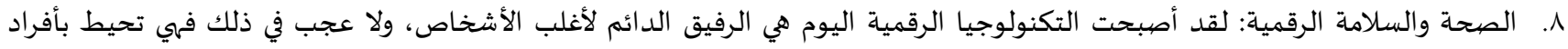

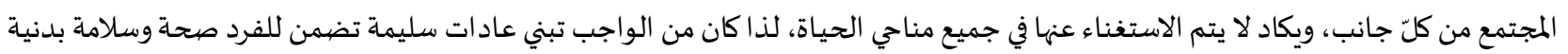
ونفسية من هذا الاستخدام، وهو ما يهتم باه محور الصحة والسلامة الرقمية، حيث عرفته بأنه جميع الإرشادات والاحتياطات اللازمة لضمانيان

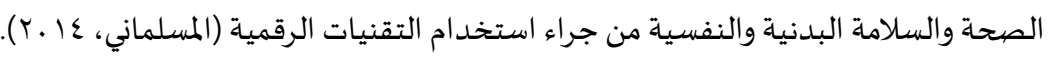
9.

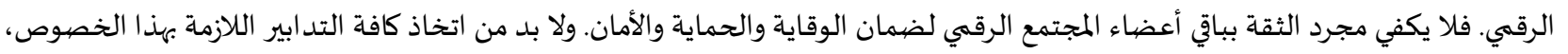
فنحن نضع الأقفال على أبواب بيوتنا، وأجهزة الإنذار في منازلنا لتوفير مستوى معين من الحماية. ولا بد من تطبيق أمثلة مباشرة في المجتمع الرقيهي.

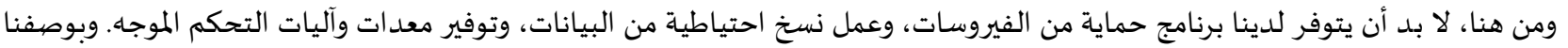

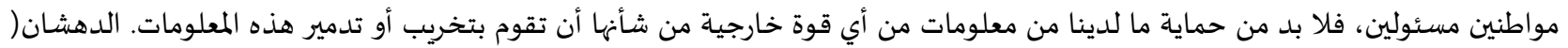

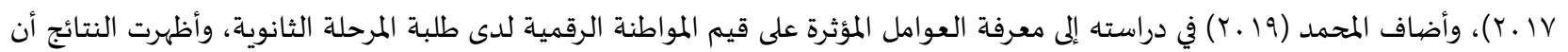

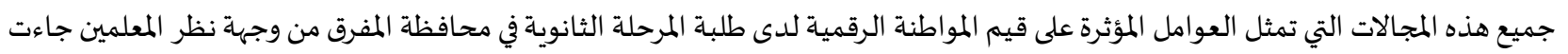

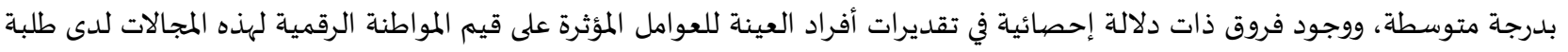

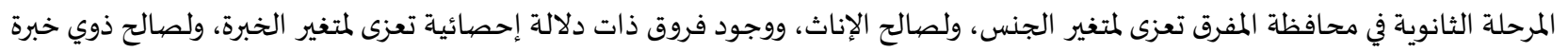
أكثر من • ا سنوات، وعدم وجود فروق تعزى لمتغير المؤهل العلمي، ووجود فروق تعزى لمتغير الدورات التدرببية، ولصالح الحاصلين على دورة

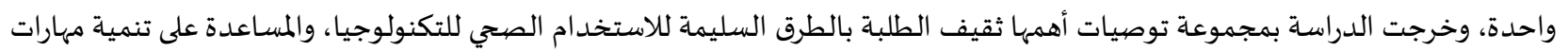
التواصل الرقمي بين الطلبة والمجتمع المحلي.

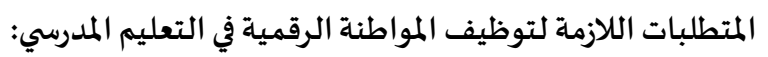

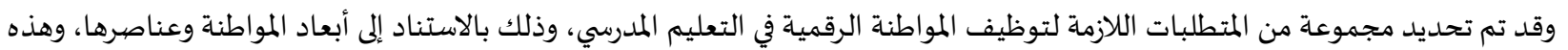

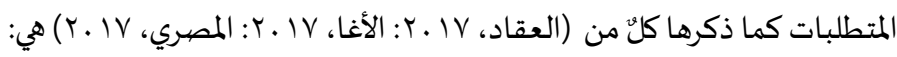


أولا: تمكين الاتصال والتواصل داخل المؤسسة التعليمية: وهذا يتطلب توفير شبكة انترنت، وأجهزة وتقنيات رقمية حديثة، وبرمجيات تعليمية

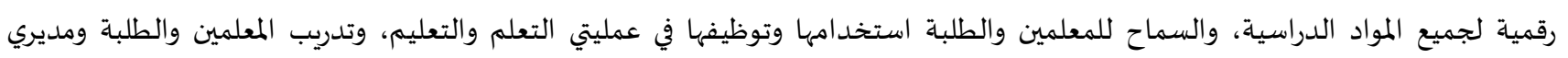
المؤسسات التعليمية في مجال التقنيات الرقمية.

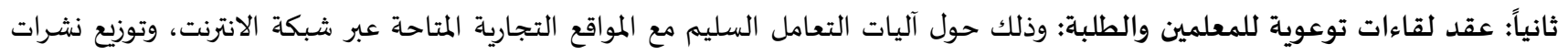

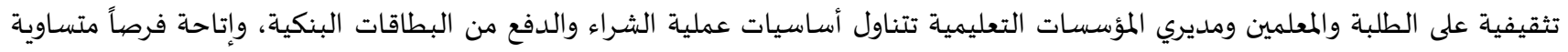

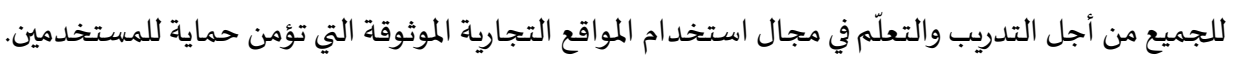

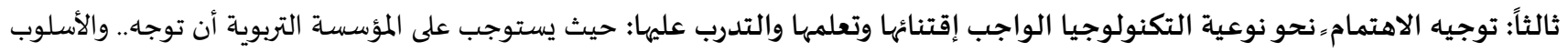

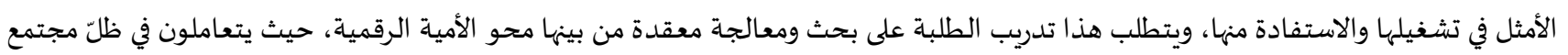

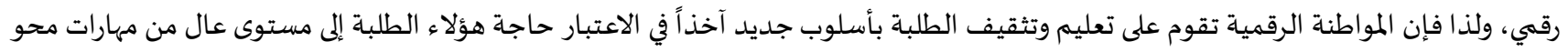

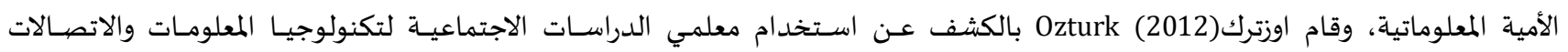

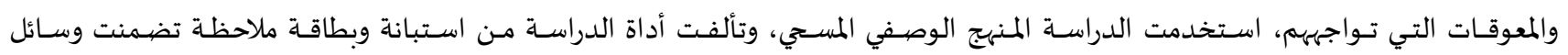

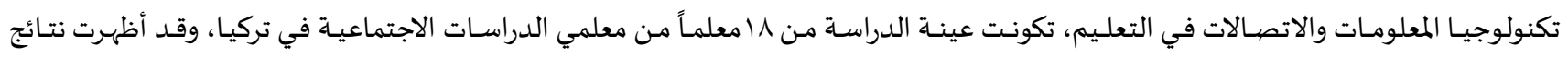

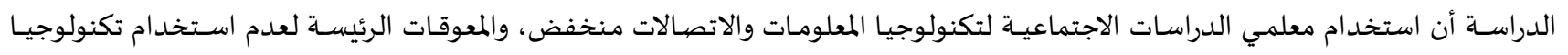

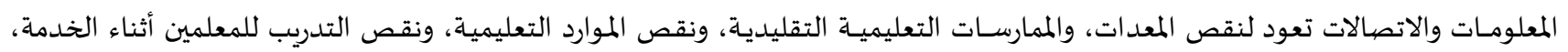
وعدم وجود الوقت الكافي لاستخد امها.

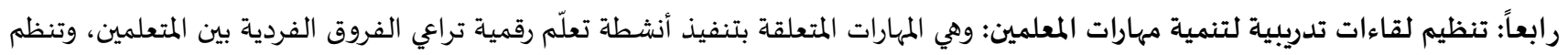

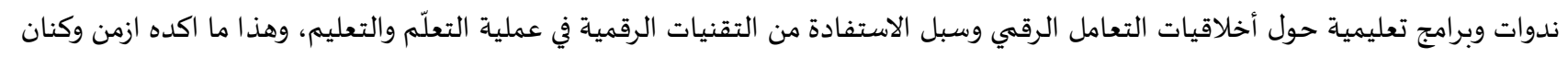

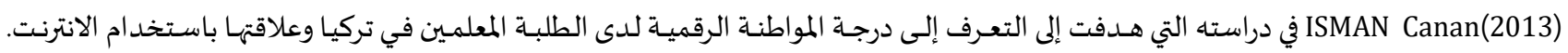

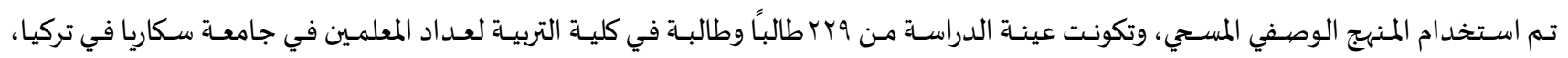

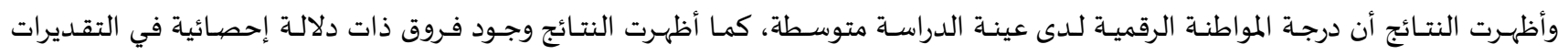

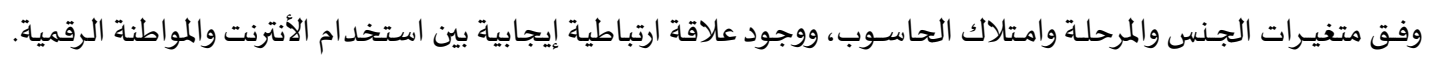

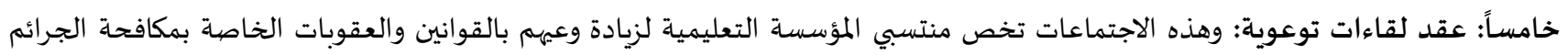

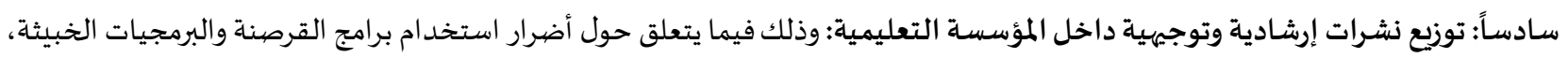

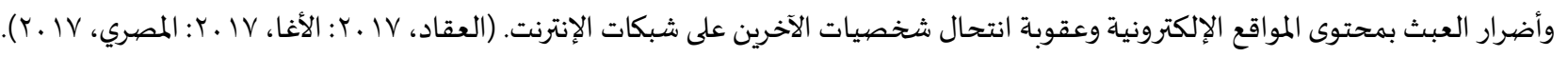

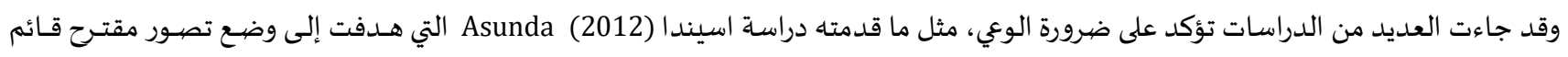

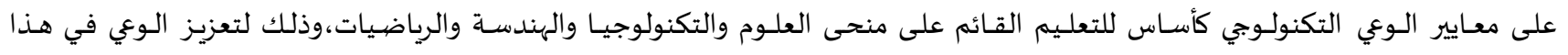

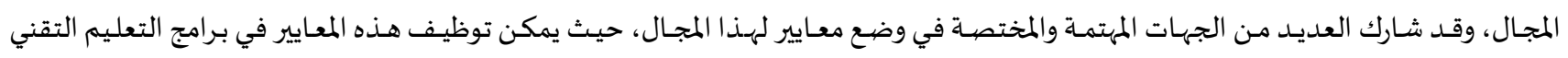

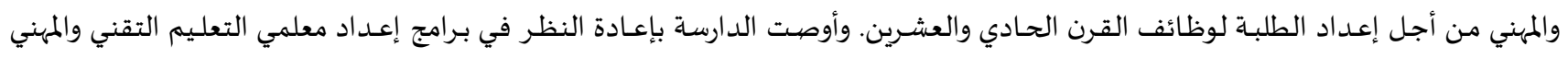

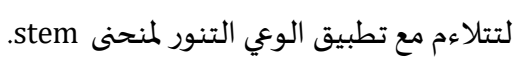

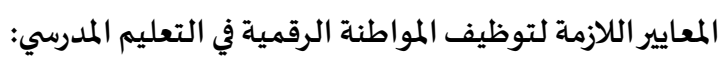

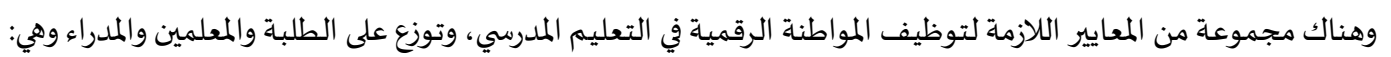

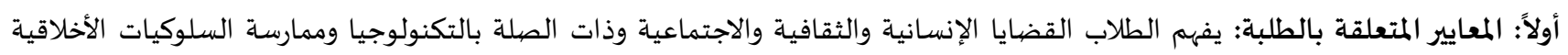

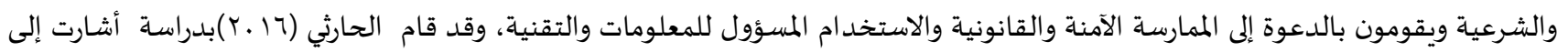

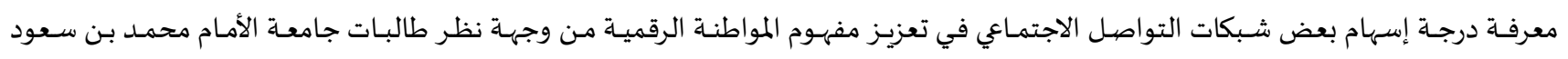

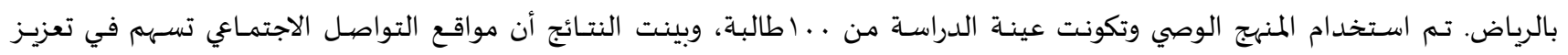

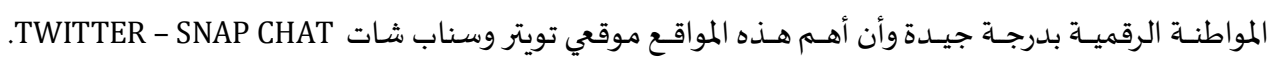

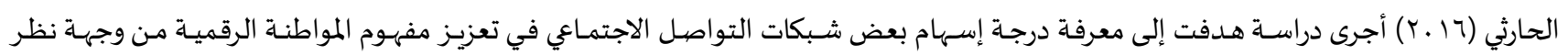

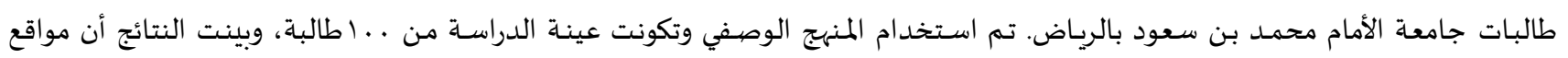

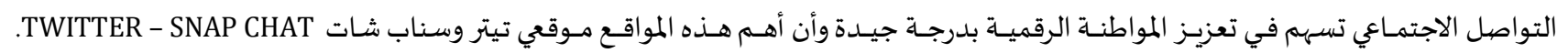


ثانياً: المعايير المتعلقة بالمعلمين: حيث يجب على المعلم مسـاعدة الطلبة على فهم التكنولوجيا الرقمية وقيمها التي تجعلهم بالمعنى الحقيقي مواطنين من العالم، على النحو التالي: يجب ألاّ ينظر الطلاب إلى التكنولوجيا على أهها مجرد مجموعة من الألعاب والأدوات تسمح للأفراد بالتواصل. الوعي بمشاركات الطلبة في العالم الافتراضي الرقهي وقيماه. تضمين البيئة الافتراضية بتفاعلاتها المختلفة في أنشطتهم وممارساتهم التدريسية. إتقان لمهارات البحث عن المعلومات والتعلم مدى الحياة.

امتلاك المعرفة حول كيف ولماذا يمكن المساهمة في للمجتمع الكوني الرقهي على الإنترنت، وكيف يكون معلماً رقمياً مسؤولاً.

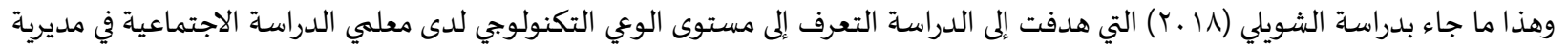
تربية إربد الأولى وعلاقته بالمواطنة الرقمية .تم استخدام المنهج الوصفي، واستبانتين تضمنتا فقرات الوعي التكنولوجي وفقرات المواطنة الرقمية، وتكونت عينة الدراسة من(ץ ع () معلماً ومعلمة من معلمي الدراسات الاجتماعية في المدارس الحكومية التابعة لمديرية تربية إبرد الأولى. وأظهرت النتائج

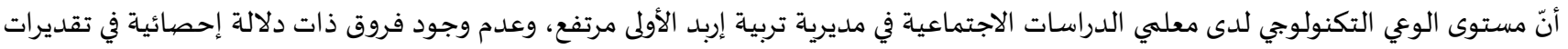

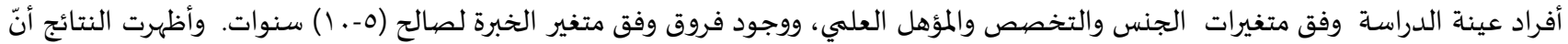

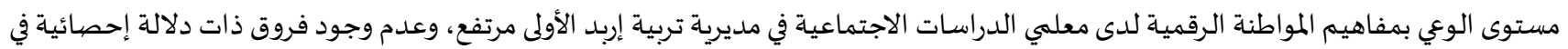
تقديرات أفراد عينة الدراسة وفق متغيرات الخبرة والتخصص والمئمأهل العلمي، ووجود فروق وفق متغير الجنس لصالح الذكور. وأظهرت النتائج وجود علاقة ارتباطية إيجابية بين مستوى الوعي التكنولوجي ومفاهيم المواطنة الرقمية. وفي ضوء النتائج قدم الباحث توصيات عدة عدة منها :دعم الوعي التكنولوجي في مجالي المعرفة والمهارات.

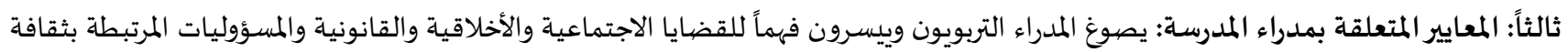
رقمية متطورة ويقومون على كفالة الفرص المتساوية للحصول على الأدوات والموارد الرقمية الملائمة لتلبية احتياجات جميع الطلاب لتعزيز التفاعلات الاجتماعية المسؤولة ذات الصلة باستخدام التكنولوجيا والمعلومات، ويكونون قدوة في تطبيق ذلك ومن خلال ما سبق يخلص الباحث إلى القول بأن تفعيل الاتصال والتواصل الرقمي داخل المؤسسة التربوية يتطلب توفير شبكة إنترنت، وأجهزة وتقنيات رقمية حديثة، وبرمجيات الميات تعليمية رقمية لجميع المواد الدراسية، والسماح للمعلمين والطلبة استخد امها وتوظيفها في عمليتي التعليم والتعلم، وتدريب المعلمين والطلبة ومديري المؤسسات التعليمية في

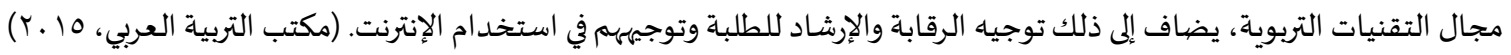

\section{إجراءات الدراسـة:}

أولاً: منهج الدراسـة والتصيميم التجريبي:

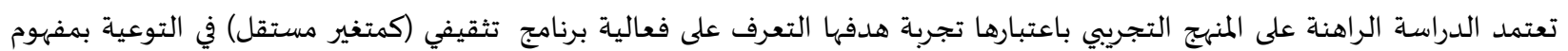
المواطنة الرقمية لدى عينة من السامعين والصهم (كمتغير تابع) والذي تم تقديمه للمجموعة التجريبية والذي يقوم على التدريب والتوعياة، كما تعتمد

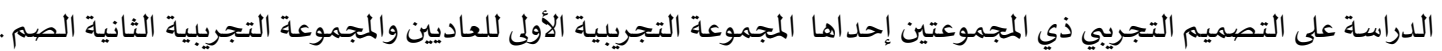
ثانياً: العينة:

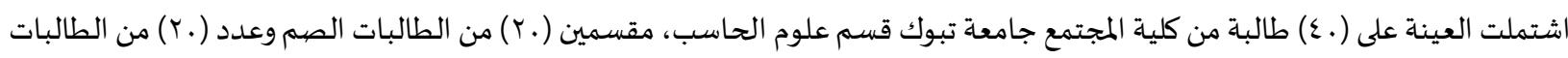
العاديين، تراوحت أعمارهم بين(1) -1 إماماً، وقد روعي في اختيار عينة الدراسة ما يلي:

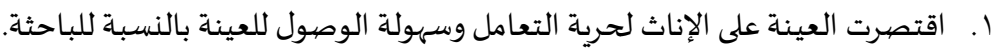

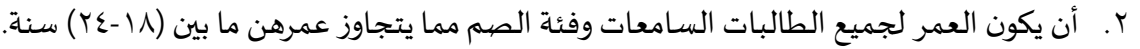

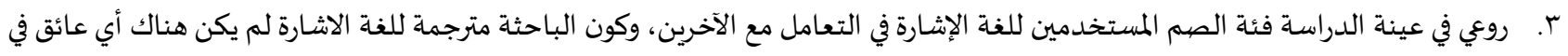
التواصل. ع. وإن جميع عينة الدراسة يمتلكن أجهزة رقمية ويستخدمن الإنترانت. 0. وتم تطبيق اختبار لجون رافن للمصفوفات المتتابعة الصور والتصحيح القياسي المحوسبة (سفيان، م . . ب) وقد تمت مجانسة أفراد المجموعاة في كل من العمر الزمنى والذكاء امتلاك أجهزة رقمية والجدول التالي يوضح ذلك: 
جدول (1): نتائج تحليل التباين بطريقة كروسكال - واليزللفروق بين رتب درجات المجموعتين ودلالاتها في المتغيرات الخاصة بالمجانسة

\begin{tabular}{|c|c|c|c|c|c|}
\hline مستوى الدلالة & ST & متوسط الرتب & العدد & المجموعة & البيان \\
\hline \multirow[t]{2}{*}{ غير دالة } & \multirow[t]{2}{*}{$r, \leq \leq \varepsilon$} & $9,9 \varepsilon$ & $r$. & التجريبية عاديين & \multirow[t]{2}{*}{ العمر } \\
\hline & & 15,19 & $r$. & التجريبية صهم & \\
\hline \multirow[t]{2}{*}{ غير دالة } & \multirow[t]{2}{*}{ ( } & 11, ro & r. & التجريبية عاديين & \multirow[t]{2}{*}{ 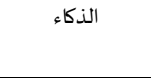 } \\
\hline & & $\mid 1,11$ & r. & التجريبية صهم & \\
\hline \multirow[t]{2}{*}{ غير دالة } & \multirow[t]{2}{*}{1,001} & 11,0 & r. & التجريبية عاديين & \multirow[t]{2}{*}{ امتلاك أجهزة ذكية } \\
\hline & & 10 & r. & التجريبية صم & \\
\hline
\end{tabular}

يتضح من الجدول السـابق عدم وجود فروق بين المجموعتين في متغيرات العمر والذكاء وامتلاك أجهزة ذكية مما يعنى تجانس المجموعتين في هذه

المتغيرات.

ثالثًًاً: أدوات الدراسـة:

ا ـ ـ مقياس المواطنة الرقمية (إعداد الباحثة):

قامت الباحثة بإعداد مقياس المواطنة الرقمية للعاديين والصيم وقد تكون من عدة أبعاد: إعداد

السلوك الرقمي: كيفية التعامل بشكل حضياري عبر الانترنت، والاتصال الرقمي: التبادل والتواصل الرقهي بين الافراد عبر الانترنت، والأمن الرقي:

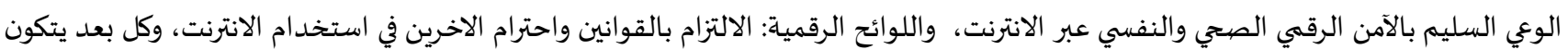
من عشر فقرات لكل بند من البنود الاربعة بإجمالي اربعين فقرة.

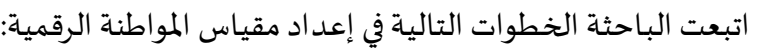

ا. الاطلاع على المقاييس في مجال المواطنة الرقمية سواء التي صممت للعاديين أو للمعاقين الموجودة بالدراسات والأبحاث العلمية .

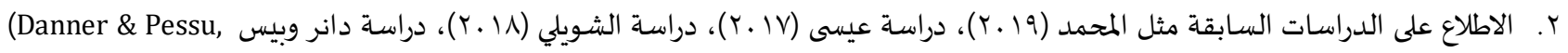

(2013، ازمن وكنان (ISMAN \& Canan, 2013) التي تناولت المواطنة الرقمية عامة ولدى المعاقين بصفة خاصة.

r. في ضوء ما سبق تم إعداد مقياس للمواطنة الرقمية ويشتمل على المحاور التالية:

$$
\begin{aligned}
& \text { أ) السلوك الرقهي } \\
& \text { ب) الاتصال الرقي الاسي } \\
& \text { ج) الأمن الرقمي } \\
& \text { د) اللوائح الرقمية الرقية }
\end{aligned}
$$

وقد شمل كل محور من المحاور السابقة على عشر بنود (فقرات) في صورة المقياس النهائية بعد التحكيم.

صيدق المقياس: (صدق المحكمين) تم عرض المقياس على مجموعة من الخبراء والمحكمين من تخصص المص علم النفس والتربية الخاصة وعددهم (م)

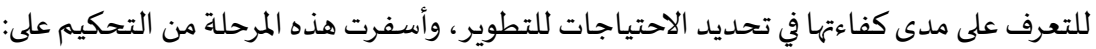

تم استبعاد العبارات التي حققت نسبة أقل من 1. ٪ من رأي المحكمين.

وافق غالبية الخبراء على محاور وعبارات المقياس مع تعديل صياغة بعض الفقرات.

هذا وقد بلغت عدد فقرات المقياس الأبعاد الأربعة على (.ع) مفردة في صورته الهائية.

وقد تم تحديد تعليمات إجابات المقياس وفق أسلوب ليكرت متدرج البدائل.

وتم إجراء الملاحظات المقترحة والتي أجمع عليها المحكمين وبذلك تم التحقق من صدق المحكمين للمقياس وطبق بصورته النهائية على الطالبات.

\begin{tabular}{|c|c|}
\hline معامل الارتباط & البنود \\
\hline .,人91 & السلوك الرقيم \\
\hline .91r & الاتصال الرقهي \\
\hline . & الأمن الرقهي \\
\hline ·, ᄉN & اللوائح الرقمية \\
\hline
\end{tabular}
الصيدق البنائي: لتحديد الصددق تم حساب معاملات ارتباط بيرسون لقياس العلاقة بين درجة كل بعد من أبعاد المقياس والدرجة الكلية للمقياس كما هو موضح بالجدول:

جدول (r): معاملات الارتباط لأبعاد المقياس والدرجة الكلية للمقياس (العينة الاستطلاعية ن=.ع)

يتضح من الجدول أن جميع معاملات الارتباط دالة إحصائياً وبدرجة قوية عند مستوى ال ., . وبذلك تعد بنود المقياس صادقة لما وضعت لقياسه. 
ثبات المقياس:

وقد تم التطبيق الاستطلاعي للمقياس على مجموعة من الطلاب العاديين والصم خارج العينة الاساسية وعددهم (.ع)، وذلك لتحديد معامل

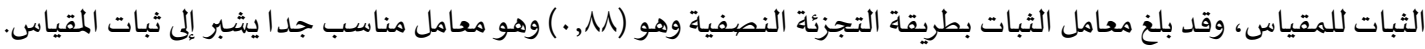

معامل الثبات بطريقة ألفاكرونباخ لبنود المقياس وفقراته كما يوضحها الجدول(r) :

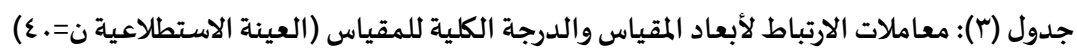

\begin{tabular}{|c|c|c|}
\hline معامل الارتباط & عدد الفقرات & البنود البنود \\
\hline$\cdot, \wedge$ & 1. & السلوك الرقمي \\
\hline$\cdot, 19$ & 1. & الاتصال الرقمي \\
\hline$\cdot, \wedge$ & 1. & الأمن الرقمي \\
\hline$\cdot, \lambda V$ & 1. & اللوائح الرقمية \\
\hline., 9. & $\varepsilon$. & المقياس الكلي \\
\hline
\end{tabular}

يتضح من الجدول السابق لجمع فقرات المقياس بطريقة ألفا كرونباخ اجو, . وهذ يعني أن معامل الثبات مرتفع.

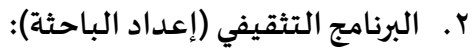

مصيادربناء البرنامج:

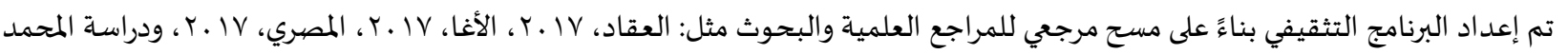

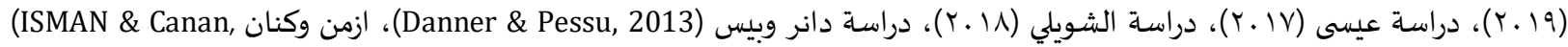

(2013)

خبرة الباحثة بمجال التربية الخاصة ومجال تخصصيها الدقيق الإعاقة السمعية، وخبرتها بإعداد البرامج للصهم وترجمتها بلغة الإشـارة، وكون الباحثة مشرفة برنامج الصهم في التعليم الجامعي جعلها أقرب معرفة بخصائصهم التعليمية والاجتماعية، ساهم ذلك بشكل فعال في بناء

البرنامج.

هدف البرنامج: يهدف البرنامج التثقيفي إلى تقديم الوعي بمفهوم المواطنة الرقمية للطالبات العاديين والصهم بالجامعة.

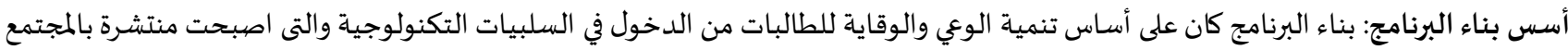

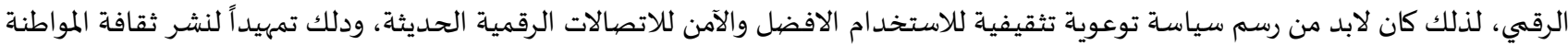

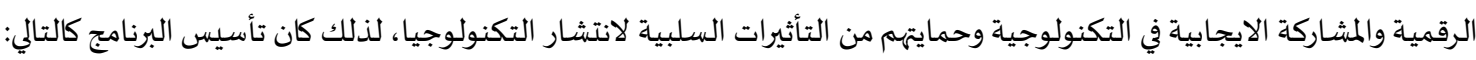
ارتباط محتوى البرنامج بأهد افها.

تنوع الأساليب المستخدمة داخل البرنامج (ورش، محاضرة، ندوة، أنشطة). تم تقديم محتوى البرنامج وفقا لاحتياجات كلا من الطالبات العاديين والصهم. تقديم الخبرات في مجال المواطنة الرقمية بأبعادها الأربعة بشكل متدرج من التعرف بالمفهوم بالمواطنة الرقمية السلوك الرقهي والاتصال الرقمي والأمن الرقمي واللوائح الرقمية. أسـاليب التدريس المستخدمة بالبرنامج: المناقشة والحوار

الأدوات المستخدمة بالبرنامج:

البروجكتر (جهاز العرض فوق الرأسي) 
مكان ومدة تنفيذ البرنامج التثقيفي:

تم تطبيق البرنامج بكلية المجتمع قسم علوم الحاسب (حيث هو القسم الوحيد في الوقت الحالي بالجامعة الذى تم إلحاق الصهم باه على مستوى

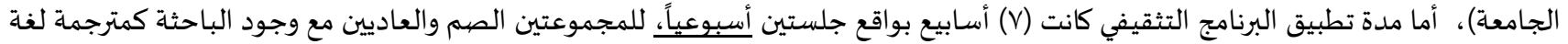

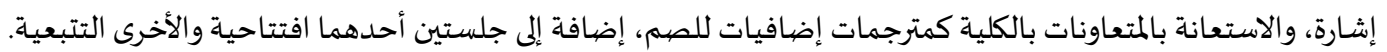

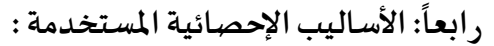
هذا وقد تمثلت الأساليب الإحصائية المستخدمة في الأساليب البارامترية التالية: استخدام اختبار ت t-test للفروق بين المجموعات وقد تم استخدامه بناءً على دراسة خصائص متغيرات الدراسة (عبد الحميد، 17 ـ ب)، وذلك من خلال حزمة البرامج الإحصائية للعلوم الاجتماعية والمعروفة اختصارا ب.Spss.V.13. نتائج الدراسة: أولاً: نتائج التساؤل الأول: للإجابة علي تساؤل الدراسة الذي ينص على (هل توجد فروق ذات دلاتلة إلهائ إحصائية بين متوسطي رتب درجات مقياس المواطنة الرقمية للمجموعتين التجريبيتين "عاديين وصهم" في القياس القبلي قبل بدء البرنامج التثقيفي؟) استخدمت الباحثة إختبار الفروق بين المتوسطات الحسابية T-Test، الهدف معرفة مدى وجود فروق واضحة بين المجموعتين وكانت النتائج كما يوضحها الجدول التالي:

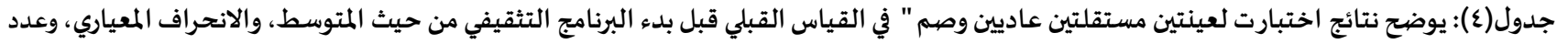

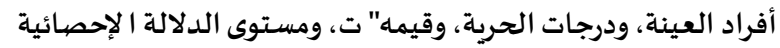

\begin{tabular}{|c|c|c|c|c|c|c|}
\hline مستوى الدلالة & قيمة ت & درجة الحرية & $\varepsilon$ & 5 & ن & المجموعات \\
\hline \multirow{2}{*}{., $1 \varepsilon_{0}$} & \multirow[t]{2}{*}{$1, \sum \wedge$} & \multirow[t]{2}{*}{$r \wedge$} & $\varepsilon, i v$ & $\Lambda \varepsilon, 7$. & $r$ r. & المجموعة التجريبية (عاديين-قبلي) \\
\hline & & & $11, \mathrm{~V}$. & $\Lambda ., \varepsilon \mathrm{V}$ & $r$. & المجموعة التجريبية (صم - قبلي) \\
\hline
\end{tabular}

ويتضح من الجدول السابق عدم وجود فروق دالة إحصائيا عند مستوى (ا ... ) على مقياس المواطنة الرقمية أفراد المجموعة التجريبية عاديين وصهم قبل تطبيق البرنامج. ثانياً: نتائج التساؤل الثاني: للإجابة على تساؤل الدراسة الذي ينص على (هل توجد فروق ذات دلالة إحصائية بين متوسطي رتب درجات مقياس المواطنة الرقمية للمجموعة

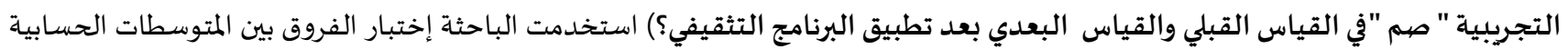
T-Test الهدف معرفة مدى وجود فروق واضحة بين المجموعة في القياسين وكانت النتائج كما يوضحها الجدول التالي: جدول(0): يوضح نتائج اختبارت لعينة الصهم" في القياس القبلي والبعدي من حيث المتوسط، والانحراف المعياري، وعدد أفراد العينة، ودرجات الحرية، وقيمه" ت، ومستوى الدلالة الإحصبائية

\begin{tabular}{|c|c|c|c|c|c|c|}
\hline مستوى الدلالة & 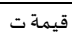 & درجة الحرية & $\varepsilon$ & م & ن & المجموعات \\
\hline \multirow[t]{2}{*}{., .1} & \multirow[t]{2}{*}{$\varepsilon, \varepsilon 9$ १ } & \multirow[t]{2}{*}{ r } & $11, \mathrm{~V}$. & 1., $\varepsilon \mathrm{V}$ & $r$. & المجموعة التجريبية (صم-قبلي) \\
\hline & & & A, rY & $M, 1 \varepsilon$ & r. & لمجموعة التجريبية (صم - بعدي) \\
\hline
\end{tabular}

ويتضح من الجدول السابق وجود فروق دالة إحصائياً عند مستوى ( . .. ) على مقياس المواطنة الرقمية أفراد المجموعة التجريبية الصهم قبل

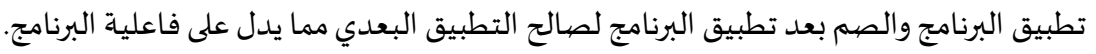
ثالثاً: نتائج التساؤل الثالث: الثبالث للإجابة على تساؤل الدراسة الذي ينص على (هل توجد فروق ذات دلاتلة إحصيائية بين متوسطي رتب درجات مقياس المواطنة الرقمية للمجموعة التجريبية "عاديين " في القياس القبلي والقياس البعدي بعد تطبيق البرنامج التثقيفي؟) استخدمت الباحثة إختبار الفروق بين المتوسطات

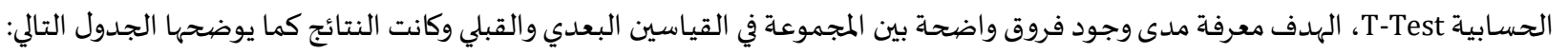
جدول(7): يوضح نتائج اختبارت لعينة العاديين في القياس القبلي والبعدي من حيث المتوسط، والانحراف المعياري، وعدد أفراد العينة، ودرجات الحرية، وقيمه" ت، ومستوى الدلالة الإحصائية

\begin{tabular}{|c|c|c|c|c|c|c|}
\hline مستوى الدلالة & قيمة ت & درجة الحرية & $\varepsilon$ & م & ن & 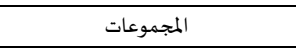 \\
\hline \multirow[t]{2}{*}{., .1} & \multirow[t]{2}{*}{ r, rov } & \multirow[t]{2}{*}{$r \lambda$} & $\varepsilon, \mid V$ & $\Lambda \varepsilon, 7$. & r. & المجموعة التجريبية (عاديين-قبلي) \\
\hline & & & $0, r y$ & $\wedge 9, \mathrm{~V}$. & r. & المجموعة التجرببية (عاديين - بعدي) \\
\hline
\end{tabular}


ويتضح من الجدول السابق وجود فروق دالة إحصائياً عند مستوى (1 ., .) على مقياس المواطنة الرقمية أفراد المجموعة التجريبية العاديين قبل تطبيق البرنامج والعاديين بعد تطبيق البرنامج لصالح التطبيق البعدي للعاديين مما يدل على فاعلية البرنامج. رابعاً: نتائج التساؤل الر ابع:

للإجابة على تساؤل الدراسة الذي ينص على (هل توجد فروق ذات دلالة إحصائية بين متوسطي رتب درجات مقياس المواطنة الرقمية للمجموعتين التجريبيتين "عاديين وصيم" في القياس البعدي بعد تطبيق البرنامج التثقيفي؟) استخدمت الباحثة إختبار الفروق بين المتوسطات

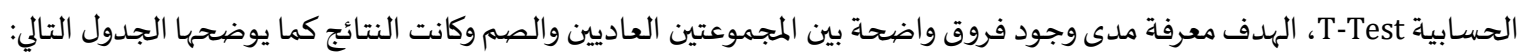
جدول(V): يوضح نتائج اختبارت لعينتين مستقلتين عاديين وصيم في القياس البعدي من حيث المتوسط، والانحراف المعياري، وعدد أفراد العينة، ودرجات الحرية، وقيمه" ت، ومستوى الدلالة الإحصيائية

\begin{tabular}{|c|c|c|c|c|c|c|}
\hline مستوى الدلالة & قيمة ت & درجة الحرية & $\varepsilon$ & م & ن & المجموعات \\
\hline \multirow[t]{2}{*}{. ¿V入 } & \multirow[t]{2}{*}{.,$V 17$} & \multirow[t]{2}{*}{$r \wedge$} & $0, r T$ & $\wedge 9, \mathrm{\vee}$. & r. & المجموعة التجريبية (عاديين-بعدي) \\
\hline & & & $\Lambda, Y Y$ & $M, 1 \varepsilon$ & r. & المججموعة التجرببية (صم - بعدي) \\
\hline
\end{tabular}

ويتضح من الجدول السابق عدم وجود فروق دالة إحصائياً عند مستوى (1 . ..) على مقياس المواطنة الرقمية أفراد المجموعة التجريبيتين العاديين والصهم في القياس البعدي بعد تطبيق البرنامج، يعزى ذلك إلى فعالية البرنامج على المجمودونتين العاديين والصئم. خامساً: نتائج التساؤل الخامس: للإجابة على تساؤل الدراسة الذي ينص على (هل توجد فروق ذات دلانلة إحصائية بين متوسطي رتب درجات مقياس المواطنة الرقمية

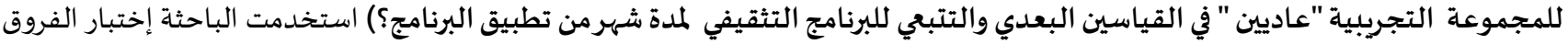
بين المتوسطات الحسابية T-Test، الهدف معرفة مدى وجود فروق واضحة بين المجموعتين، وكانت النتائج كما يوضحها الجدول التالي: جدول( ) ): يوضح نتائج اختبارت لعينة العاديين في القياس البعدي والتتبعي من حيث المتوسط، والانحراف المعياري، وعدد أفراد العينة، ودرجات الحرية، وقيمه" ت، ومستوى الدلالة الإحصيائية

\begin{tabular}{|c|c|c|c|c|c|c|}
\hline مستوى الدلالة & قيمة ت & درجة الحرية & $\varepsilon$ & b & ن & المجموعات \\
\hline \multirow[t]{2}{*}{$\cdot, \lambda \cdot \Lambda$} & \multirow[t]{2}{*}{., TEV } & \multirow[t]{2}{*}{ ru } & $0, r r$ & $\wedge १, \vee$. & r. & المجموعة التجريبية (عاديين-بعدي) \\
\hline & & & $9,1 \mathrm{~V}$ & $19,1$. & r. & لمجموعة التجريبية (عاديين - تتبعي) \\
\hline
\end{tabular}

ويتضح من الجدول السابق عدم وجود فروق دالة إحصائياً عند مستوى (1 ... ) على مقياس المواطنة الرقمية أفراد المجموعة التجريبية العاديين في القياس البعدي بعد تطبيق البرنامج والتتبعي بعد فترة من تطبيق البرنامج، يعزى ذلك إلى فعالية البرنامج على المجموعة التجريبية عاديين في مئي القياسين. سادساً: نتائج التساؤل السـادس: للإجابة على تساؤل الدراسة الذي ينص على (هل توجد فروق ذات دات دلالة إحصائية بين متوسطي رتب درجات مقياس المواطنة الرقمية للمجموعة التجريبية " صم " في القياس البعدي والقياس التتبعي على البرنامج التثقيفي؟) استخدمت الباحثة إختبار الفروق بين المتوسطات

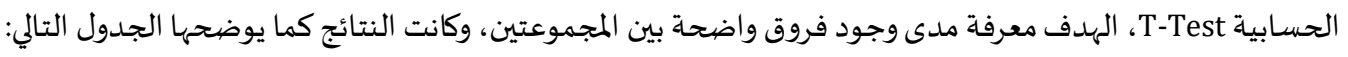

جدول(9): يوضح نتائج اختبارت لعينة الصيم في القياس البعدي والتتبعي من حيث المتوسط، والانحراف المعياري، وعدد أفراد العينة، ودرجات الحرية، وقيمه "ت، ومستوى الدلالة الإحصائية

\begin{tabular}{|c|c|c|c|c|c|c|}
\hline مستوى الدلالة & قيمة ت & درجة الحرية & $\varepsilon$ & م & ن & المجموعات \\
\hline \multirow[t]{2}{*}{$\cdot, \wedge \mathrm{VI}$} & \multirow[t]{2}{*}{ 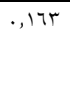 } & \multirow[t]{2}{*}{ ru } & $\Lambda, Y Y$ & $\Lambda, 1 \varepsilon$ & r. & المجموعة التجريبية (صم-بعدي) \\
\hline & & & $0, r 9$ & $\Lambda 9, \mathrm{rT}^{\mathrm{N}}$ & r. & المجموعة التجريبية (صم - تتبعي) \\
\hline
\end{tabular}

ويتضح من الجدول السابق عدم وجود فروق دالة إحصائياً عند مستوى (1 ...) على مقياس المواطنة الرقمية أفراد المجموعة التجريبية الصهم في القياس البعدي بعد تطبيق البرنامج والتتبعي بعد فترة من تطبيق البرنامج، يعزى ذلك إلى فعالية البرنامج على المجموعة التجبريبية صهم.

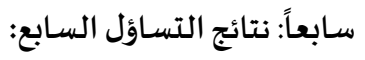
للإجابة على تساؤل الدراسة الذي ينص على (هل توجد فروق ذات دلالة إحصائية بين متوسطي رتب درجات مقياس المواطنة الرقمية

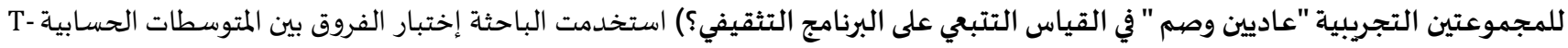

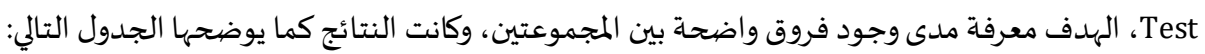


جدول( • (): يوضح نتائج اختبارت لعينتين مستقلتين عاديين وصهم" في القياس التتبعي من حيث المتوسط، والانحراف المعياري، وعدد أفراد العينة، ودرجات الحرية، وقيمه" ت، ومستوى الدلالة الإحصيائية

\begin{tabular}{|c|c|c|c|c|c|c|}
\hline مستوى الدلالة & قيمة ت & درجة الحرية & $\varepsilon$ & م & ن & المجموعات \\
\hline \multirow[t]{2}{*}{., 904} & \multirow[t]{2}{*}{., .09} & \multirow[t]{2}{*}{$r \wedge$} & 9,18 & ^9,1. & r. & المجمموعة التجريبية (عاديين-تتبعي) \\
\hline & & & $0, r 9$ & 19,rr & r. & المجموعة التجريبية (صم- تتبعي) \\
\hline
\end{tabular}

ويتضح من الجدول السابق عدم وجود فروق دالة إحصائياً عند مستوى (1 . ..) على مقياس المواطنة الرقمية أفراد المجموعة التجريبيتين العاديين

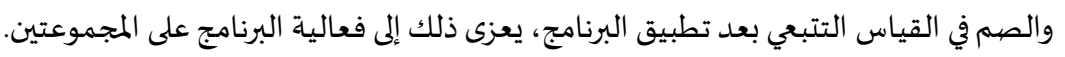

تفسيرومناقشة النتائج:

أظهرت النتائج إن البرنامج التثقيفي لـه تأثير إيجابي وفعال على مستوى الأعداد والتنفيذ على الطالبات، وذلك من خلال التعزيز الإيجابي الذى ظهر لدى الطالبات في مستوى قيم المواطنة، والنتائج التي وضحت من التطبيق الفروق الإحصائية بين التطبيق القبلي والبعدي للمجموعتين التجريبيتين

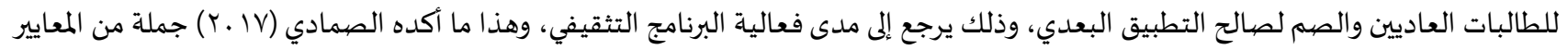
التي لابد أن يلتزم بها الطلبة عند استخدامهه للوسائط الرقمية، والمتمثلة في مجموعة الحقوق والواجبات التي يتمتعون بها ويلتزمون بها أثناء

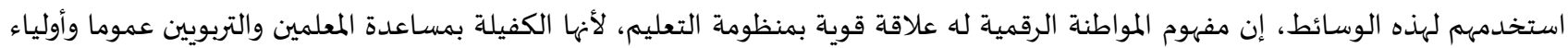
الأمور لفهم ما يجب على الطلاب معرفته من أجل استخدام التكنولوجيا بشكل مناسب، والمواطنة الرقمية هي أكثر من مجرد أداة تعليمية، بل هي

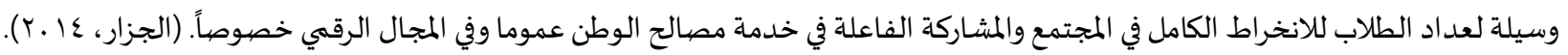

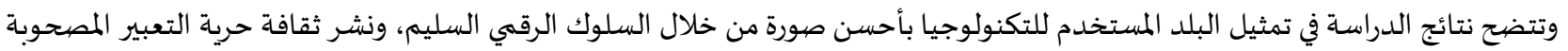

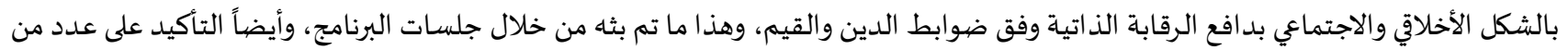

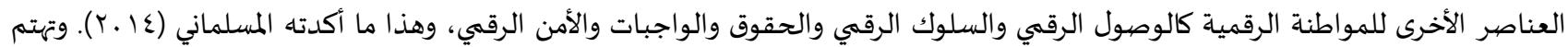
المواطنة الرقمية بنشر ثقافة الاحترام الرقهي بين الأفراد وتدريههم ليكونوا مسؤولين في ظل مجتمع رقي جديد، ليتصرفوا بتحضر، مراعين القيم

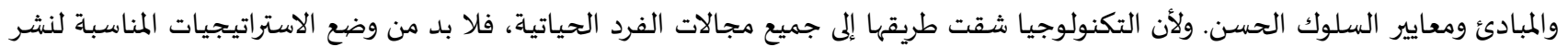

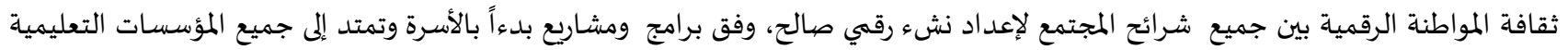

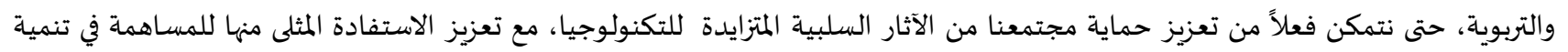
مجتمع المعرفة وبناء الاقتصاد الرقمي الوطني .ولا بد للجميع أفراداً ومؤسسات من أن يتحمل مسؤوليته تجاه هذا الموضونوع الحيوي المهم. (الشويلي

وتعزو الباحثة تقارب الفروق بين الطالبات العاديات والصمم في فهم المواطنة الرقمية، إلى أن مفهوم المواطنة الرقمية مفهوم حديث وإنه كلما زاد

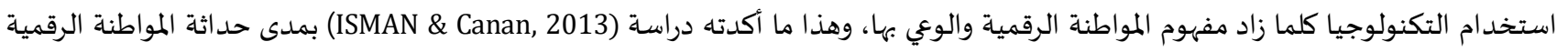

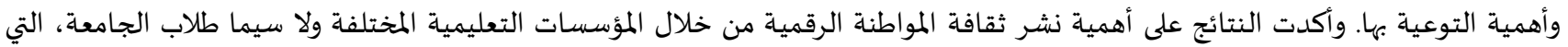
أوضحت النتائج وقبل البرنامج التثيقفي عدم وجود الوعي الكافي بأهمية الاستخدام الأمثل للتحول الرقمي الذي اخترق كل مجالات الحياة، وهذا ما

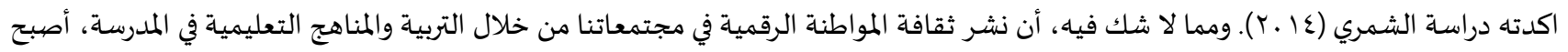

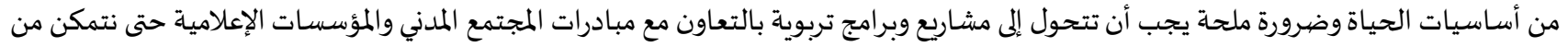

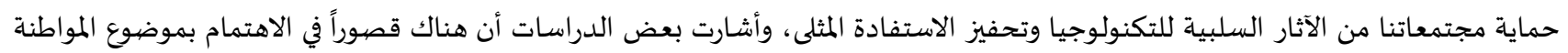
الرقمي. ومن خلال ما سبق يُستنج أن أهمية دور المؤسسات التربوية في توجيه وتوعية الطلبة لديهم في الاستخدام المناسب للتكنولوجية الحديثة، وتطوير

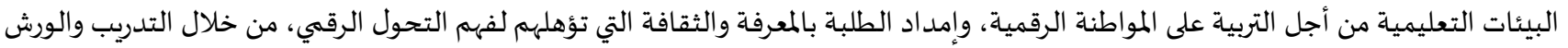

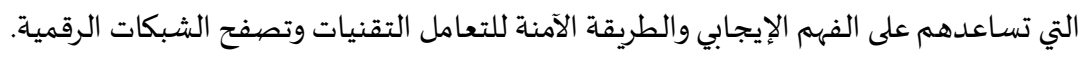
توصيات الدراسة: في ضوء ما توصلت إليه الدراسة نوصي بما يلي: إجراء المزيد من الدراسات حول مفاهيم وقيم المواطنة الرقمية على مراحل دراسية أخرى للوصول إلى تصور متكامل عن تلك القيم وإمكانية 
دعـم مفـاهيم القـانون والاتصـال الرقمي، والأمـن وقواعـد السـلوك الرقمي، والحقـوق والمسؤوليات الرقمية، والثقافة الرقمية ضرورة إجراء المزيد من الدراسات المكثفة الكمية والنوعية حول موضوع المواطنة الرقمية لقلة تناولها في الدراسات العربية علما أننا بأمس الحاجة لها في العالم العربي. ضرورة توفير الوصول الرقمي للجميع بلا استثناء داخل المؤسسات التعليمية. ضرورة تضمين المناهج التعليمية بمفاهيم المواطنة الرقمية وأساليب تفعيلها على أرض الواقع. ضرورة عقد دورات تدربية للطلبة ومعلميهم تستهدف زيادة وعيهم بحقوقهم وواجباتهم الرقمية. المقترحات للدراسـات المستقبلية:

إجراء دراسـة عن مدى تطبيق مديرات المدارس لمفهوم المواطنة الرقمية في المدارس والجامعات. إجراء دراسة مماثلة للدراسة الحالية بالجامعات على البنين من الصهم والعاديين وعلى مستوى ذوي الإعاقة ممن يستخدموا التكنولوجيا والتواصل الرقمي. إجراء دراسة مقارنه بين درجة تطبيق المواطنة الرقمية بين المراحل المختلفة من التعليم.

ا. الأسمري، شهد سعيد. (10 ـ ب). "المواطنة الرقمية وثقافة الاستخدام الآمن للإنترنت للكبار- والصغار وخطوات الحماية طريق الأمان". تقنيات التعليم، كلية التربية، جامعة الأميرة نورة.

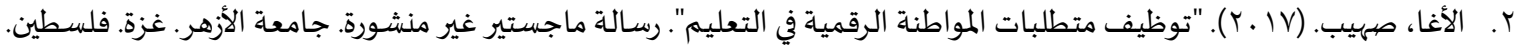

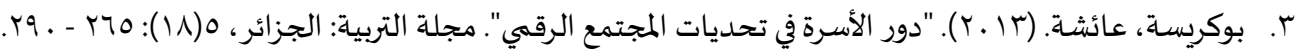
ع. الجزار، هالة. (ع ا. ب). "دور المؤسسات التربوية في غرس قيم المواطنة الرقمية تصور مقترح". مجلة دراسات عربية في التربية وعلم النفس:ا (7ه):

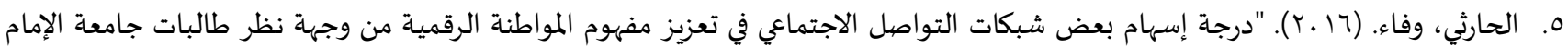
محمد بن سعود الإسلامية بالرياض". رسالة ماجستير غير منشورة. جامعة الإمام محمد بن سعود السلامية. السعودية.

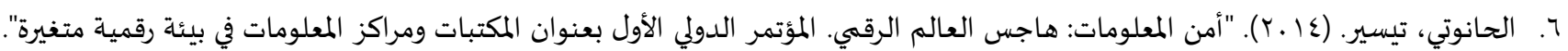
الأردن: جمعية المكتبات والمعلومات الأردنية.

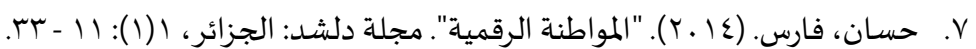

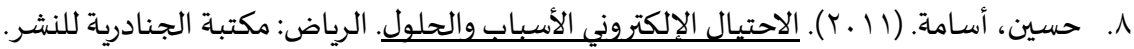

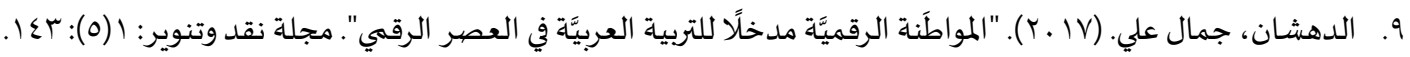

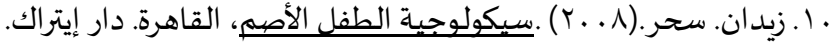
ا ـ سفيان، نبيل. (1 . . †). "اختصيار وتقنين وحوسبة اختبار الذكاء لرافن المصفوفات المتتابعة القياسي على كلية الجامعة في اليمن". المجلة العلمية في كلية التربية: جامعة ذمار، ان(0)

Y ا. الشخشير، حلا. (. ا .Y). "مستوى التنمية المهنية لدى أعضياء الهيئة التدريسية في جامعة النجاح الوطنية". مطبوعات جامعة النجاح. فلسطين.

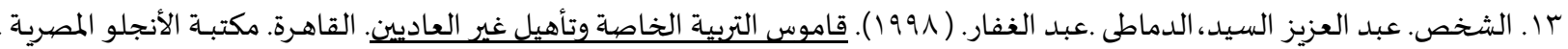
ع ا. الشمري، مشعل. (V. . اY). "درجة ممارسة معلمي اللغة العربية للكفايات التكنولوجية التعليمية من وجهاة نظرهم في منطقة الجوف في المملكة العربية السعودية". رسالة ماجستير غير منشورة. الجامعة الأردنية. عمان. المعان.

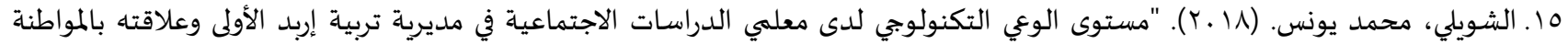

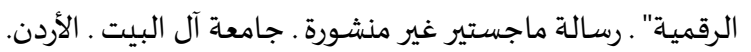

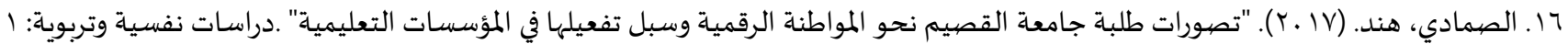

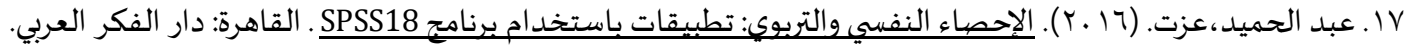

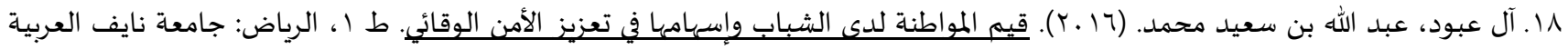
للعلوم الأمنية. 
9 ا. العقاد، ثائرة. (VI ـ †). "تصور مقترح لتمكين العاملين بوزارة التربية والتعليم الفلسطينية نحو توظيف متطلبات المواطنة الرقمية في التعليم". رسالة ماجستير غير منشورة. جامعة الأزهر. غزة.

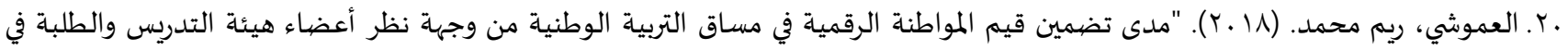
جامعات إقليم الشمال". رسالة ماجستير. المناهج العامة. جامعة آل البيت. كلية العلوم التربوية. الأردن.

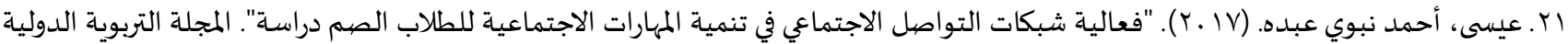

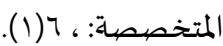

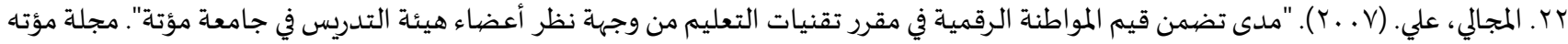

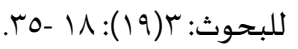

بr. المحمد، أيمن عوض. (19 ـ r). "العوامل المؤثرة على قيم المواطنة الرقمية لدى طلبة المرحلة الثانوية في محافظة المفرق من وجهة نظر المعلمين". رسالة ماجستير غير منشورة. جامعة آل البيت ـ الأردن.

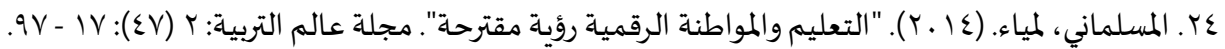
هr. المصري، مروان. شعث، أكرم. (VI . r). "مستوى المواطنة الرقمية لدى عينة من طلبة جامعة فلسطين من وجهة نظرهم". مجلة عالم التربية: $.179-1 \varepsilon 1:(1))^{r}$ جr. المعمري، ناصر. المسروي، فهد. (rا ـץ). " درجة توافر كفايات تكنولوجيا المعلومات والاتصالات لدى معلمي الدراسات الاجتماعية بمرحلة التعليم

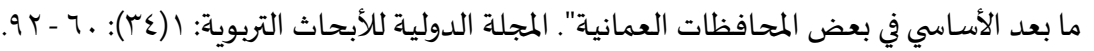
rV

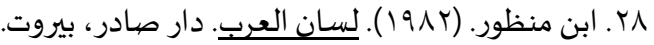

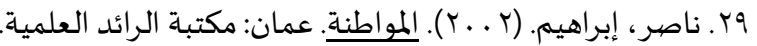

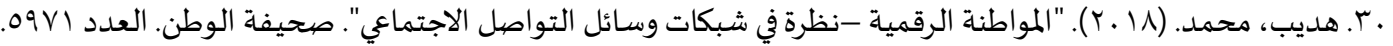

ثانياً: المراجع الأجنبية:

[1] Asunda, P. (2012). "Standards for Technological Literacy and STEM Education Delivery Through Career and Technical Education Programs", Journal of Technology Education, 23(2), 44-60, https://doi.org/10.21061/jte.v23i2.a.3.

[2] Danner, R. \& Pessu, C. (2013). "A Survey of ICT Competencies among Students in Teacher Preparation Programs at the University of Benin, Benin City, Nigeria", Journal of Information Technology Education: Research,12: 33-49, https://doi.org/10.28945/1762.

[3] Günes, G, Gökçek, T, \& Bacanak, A. (2010). "How do teachers evaluate themselves in terms of technological competencies?" Procedia Social and Behavioral Sciences, 9 (1), 1266 -1271, https://doi.org/10.1016/j.sbspro.2010.12.318.

[4] Isman, A. \& Canan G. (2013). “Digital Citizenship”, Turkish Online Journal of educational Technology, 13(1): 73-77.

[5] Mossberg, K., Tolbert, C.J. \& McNeal, R.S. (2011). Digital Citizenship: The Internet, Society, and Participation. The MIT Press, Cambridge, Massachusetts, London, England.

[6] Ohler, Jason B. (2011). Digital Community, Digital Citizen. Thousand Oaks: Corwin Press Inc.

[7] Ozturk, S. (2012). "Barriers to ITC integration into teachers' classroom practices: Lessons from a case study on social studies teachers in Turkey". World Applied Sciences Journal, 18(7): 929-944.

[8] Ribble, bailey. (2006). digital citizenship. At all grade's levels.

[9] Thompson, P. (2013). "The digital natives as learners: Technology use patterns and approaches to learning”. Computers \& Education, 65(1): 12-33, https://doi.org/10.1016/j.compedu.2012.12.022.

ثالثاً: المو اقع الإلكترونية: - م

http://blog.naseej.com/2013/07/11/\%D8\%A7\%D9\%84\%D9\%85\%D9\%88\%D8\%A7\%D8\%B7\%D9\%86\%D8\%A9\%D8\%A7\%D9\%84\%D8\%B1\%D9\%82\%D9\%85\%D9\%8A\%D8\%A9 
المجلة الدولية للدراسـات التربوية والنفسية

International Journal of Educational \& Psychological Studies (EPS)

Journal Homepage: https://www.refaad.com/views/EPSR/Home.aspx

www.refaad.com

ISSN: 2520-4149 (Online) 2520-4130 (Print)

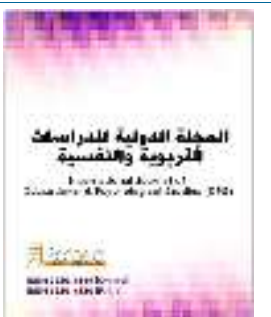

\title{
An educational program to raise awareness of the concept of digital citizenship ordinary and deaf "comparative study"
}

\author{
Sahar Zedan Zayan \\ Associate Professor of Mental Health and Special Education, Department of Special Education and Supervisor of \\ the Deaf Program, University of Tabuk, Saudi Arabia \\ Sah_zed@hotmail.com
}

Received Date : 29/2/2020

Accepted Date : 28/3/2020

DOI : https://doi.org/DOI:10.31559/EPS2020.8.2.2

\begin{abstract}
The current study aims to provide an educational program to raise awareness of the concept of digital citizenship for the deaf and the ordinary: a comparative study, and the sample included (40) students from the Community College, University of Tabuk, Department of Computer Science, divided (20) of deaf students and (20) of ordinary students, The researcher used in the study a measure of digital citizenship and an educational program prepared by the researcher, and the results have resulted in the absence of statistically significant differences between the mean scores of the digital citizenship scale for the two experimental groups and deaf in the premeasurement before the start of the educational program, and the presence of statistically significant differences between the medians of $d$ The digital citizenship scale of the experimental group for the deaf in the two dimensional pre-measurement in favor of the post-measurement after the application of the educational program, and the presence of statistically significant differences between the mean scores of the digital citizenship scale of the experimental group for the ordinary after-the-post-post-measurement for the validity of the postmeasurement after the application of the educational program, and the absence of significant differences Statistics between the mean scores of the citizenship scale for the two experimental groups and the deaf in the postmeasurement after applying the educational program, and the absence of statistically significant differences between the average scores for the citizenship scale for the two experimental groups The two ordinary and deaf children in the post and follow-up measurements of the educational program for one month after the implementation of the program.
\end{abstract}

\section{Keywords: The Educational Program; Digital Citizenship; The Deaf.}

\section{References:}

[1] 'bd Alhmyd,'zt. (2016). Alehsa' Alnfsy Waltrbwy: Ttbyqat Bastkhdam Brnamj Spss18. Alqahrh: Dar Alfkr Al'rby.

[2] Al 'bwd, 'Ebd Allh Bn S'yd Mhmd. (2016). Qym Almwatnh Lda Alshbab Weshamha Fy T'zyz Alamn Alwqa'y. T 1, Alryad: Jam't Nayf Al'rbyh Ll'lwm Alamnyh.

[3] Al'qad, Tha'rh. (2017). "Tswr Mqtrh Ltmkyn Al'amlyn Bwzart Altrbyh Walt'lym Alflstynyh Nhw Twzyf Mttlbat Almwatnh Alrqmyh Fy Alt'lym". Rsalt Majstyr Ghyr Mnshwrh. Jam't Alazhr. Ghzh.

[4] Al'mwshy, Rym Mhmd. (2018). "Mda Tdmyn Qym Almwatnh Alrqmyh Fy Msaq Altrbyh Alwtnyh Mn Wjht Nzr A'da' Hy't Altdrys Waltlbh Fy Jam'at Eqlym Alshmal". Rsalt Majstyr. Almnahj Al'amh. Jam't Al Albyt. Klyt Al'lwm Altrbwyh. Alardn.

[5] 'ysa, Ahmd Nbwy 'bdh. (2017). "F'alyt Shbkat Altwasl Alajtma'y Fy Tnmyt Almharat Alajtma'eyh Lltlab Alsm Drash". Almjlh Altrbwyh Aldwlyh Almtkhssh: 6(1).

[6] Alasmry, Shhd S'yd. (2015). "Almwatnh Alrqmyh Wthqafh Alastkhdam Alamn Llentrnt Llkbar -Walsghar Wkhtwat Alhmayh Tryq Alaman". Tqnyat Alt'lym, Klyt Altrbyh, Jam't Alamyrh Nwrh.

[7] Alagha, Shyb. (2017). "Twzyf Mttlbat Almwatnh Alrqmyh Fy Alt'lym". Rsalt Majstyr Ghyr Mnshwrh. Jam't Alazhr. Ghzh. Flstyn.

[8] Asunda, P. (2012). "Standards for Technological Literacy and STEM Education Delivery Through Career and Technical Education Programs", Journal of Technology Education, 23(2), 44-60, https://doi.org/10.21061/jte.v23i2.a.3.

[9] Bwkrysh, 'a'shh. (2013). "Dwr Alasrh Fy Thdyat Almjtm' Alrqmy". Mjlt Altrbyh: Aljza'r, 5(18): 265 - 290. 
[10] Danner, R. \& Pessu, C. (2013). “A Survey of ICT Competencies among Students in Teacher Preparation Programs at the University of Benin, Benin City, Nigeria”, Journal of Information Technology Education: Research,12: 33-49, https://doi.org/10.28945/1762.

[11] Aldhshan, Jmal 'Ely. (2017). "Almwatnh Alrqmyh Mdkhlana Lltrbyh Al'rbyh Fy Al'sr Alrqmy". Mjlt Nqd Wtnwyr: 1(5): 143.

[12] Günes, G, Gökçek, T, \& Bacanak, A. (2010). "How do teachers evaluate themselves in terms of technological competencies?" Procedia Social and Behavioral Sciences, 9 (1), 1266 -1271, https://doi.org/10.1016/j.sbspro.2010.12.318.

[13] Alhanwty, Tysyr. (2014). "Amn Alm'lwmat: Hajs Al'alm Alrqmy. Alm'tmr Aldwly Alawl B'nwan Almktbat Wmrakz Alm'lwmat Fy By'h Rqmyh Mtghyrh". Alardn: Jm'yt Almktbat Walm'lwmat Alardnyh.

[14] Alharthy, Wfa'. (2016). "Drjt Esham B'd Shbkat Altwasl Alajtma'y Fy T'zyz Mfhwm Almwatnh Alrqmyh Mn Wjht Nzr Talbat Jam't Alemam Mhmd Bn S'wd Aleslamyh Balryad". Rsalt Majstyr Ghyr Mnshwrh. Jam't Alemam Mhmd Bn S'wd Alslamyh. Als'wdyh.

[15] Hdyb, Mhmd. (2018). "Almwatnh Alrqmyh -Nzrh Fy Shbkat Wsa'l Altwasl Alajtma'y". Shyfh Alwtn. Al'dd 5971.

[16] Hsan, Fars. (2014). "Almwatnh Alrqmyh". Mjlt Dlshd: Aljza'r, 1(1): 11 - 33

[17] Hsyn, Asamh. (2011). Alahtyal Alelktrwny Alasbab Walhlwl. Alryad: Mktbt Aljnadryh Llnshr.

[18] Isman, A. \& Canan G. (2013). “Digital Citizenship”, Turkish Online Journal of educational Technology, 13(1): 73-77.

[19] Aljzar, Halh. (2014). "Dwr Alm'ssat Altrbwyh Fy Ghrs Qym Almwatnh Alrqmyh Tswr Mqtrh". Mjlt Drasat 'rbyh Fy Altrbyh W'lm Alnfs:1 (56): 385 - 418.

[20] Alm'mry, Nasr. Almsrwy, Fhd. (2013). " Drjt Twafr Kfayat Tknwlwjya Alm'lwmat Walatsalat Lda M'lmy Aldrasat Alajtma'yh Bmrhlh Alt'lym Ma B'd Alasasy Fy B'd Almhafzat Al'manyh". Almjlh Aldwlyh Llabhath Altrbwyh: 1(34): 60 - 92.

[21] Almhmd, Aymn 'wd. (2019). "Al'waml Alm'thrh 'la Qym Almwatnh Alrqmyh Lda Tlbt Almrhlh Althanwyh Fy Mhafzt Almfrq Mn Wjht Nzr Alm'lmyn". Rsalt Majstyr Ghyr Mnshwrh. Jam't Al Albyt. Alardn.

[22] Almjaly, 'ly. (2007). "Mda Tdmn Qym Almwatnh Alrqmyh Fy Mqrr Tqnyat Alt'lym Mn Wjht Nzr A'da' Hy't Altdrys Fy Jam't M'th". Mjlt M'th Llbhwth: 3(19): 18 -35.

[23] Mktb Altrbyh Al'rby Ldwl Alkhlyj. (2015). "M'ayyr Tknwlwjya Alt'lym".

[24] Abn Mnzwr. (1982). Lsan Al'rb. Dar Sadr, Byrwt.

[25] Mossberg, K., Tolbert, C.J. \& McNeal, R.S. (2011). Digital Citizenship: The Internet, Society, and Participation. The MIT Press, Cambridge, Massachusetts, London, England.

[26] Almslmany, Lmya'. (2014). "Alt'lym Walmwatnh Alrqmyh R'yh Mqtrhh". Mjlt 'Ealm Altrbyh: 2 (47): 17 - 97.

[27] Almsry, Mrwan. Sh'eth, Akrm. (2017). "Mstwa Almwatnh Alrqmyh Lda 'ynh Mn Tlbt Jam't Flstyn Mn Wjht Nzrhm". Mjlt 'alm Altrbyh: 2(13): 141 - 169.

[28] Nasr, Ebrahym. (2002). Almwatnh. 'man: Mktbh Alra'd Al'lmyh.

[29] Ohler, Jason B. (2011). Digital Community, Digital Citizen. Thousand Oaks: Corwin Press Inc.

[30] Ozturk, S. (2012). "Barriers to ITC integration into teachers' classroom practices: Lessons from a case study on social studies teachers in Turkey". World Applied Sciences Journal, 18(7): 929-944.

[31] Ribble, bailey. (2006). digital citizenship. At all grade's levels.

[32] Sfyan, Nbyl. (2008). "Akhtsar Wtqnyn Whwsbh Akhtbar Aldka' Lrafn Almsfwfat Almttab'eh Alqyasy 'la Klyt Aljam'h Fy Alymn". Almjlh Al'lmyh Fy Klyt Altrbyh: Jam'h Dmar, 1(5).

[33] Alshkhshyr, Hla. (2010). "Mstwa Altnmyh Almhnyh Lda A'da' Alhy'h Altdrysyh Fy Jam't Alnjah Alwtnyh". Mtbw'at Jam'eh Alnjah. Flstyn.

[34] Alshkhs. 'bd Al'zyz Alsyd,Aldmata .'bd Alghfar. (1998). Qamws Altrbyh Alkhash Wtahyl Ghyr Al'adyyn. Alqahrh. Mktbt Alanjlw Almsryh.

[35] Alshmry, Msh'l. (2007). "Drjt Mmarsh M'lmy Allghh Al'rbyh Llkfayat Altknwlwjyh Alt'lymyh Mn Wjht Nzrhm Fy Mntqt Aljwf Fy Almmlkh Al'rbyh Als'wdyh". Rsalt Majstyr Ghyr Mnshwrh. Aljam'h Alardnyh. 'man.

[36] Alshwyly, Mhmd Ywns. (2018). "Mstwa Alw'y Altknwlwjy Lda M'lmy Aldrasat Alajtma'yh Fy Mdyryt Trbyt Erbd Alawla W'laqth Balmwatnh Alrqmyh". Rsalt Majstyr Ghyr Mnshwrh. Jam't Al Albyt. Alardn.

[37] Alsmady, Hnd. (2017). "Tswrat Tlbh Jam't Alqsym Nhw Almwatnh Alrqmyh Wsbl Tf'ylha Fy Alm'ssat Alt'lymyh". Drasat Nfsyh Wtrbwyh: 1 (8).

[38] Thompson, P. (2013). "The digital natives as learners: Technology use patterns and approaches to learning". Computers \& Education, 65(1): 12-33, https://doi.org/10.1016/j.compedu.2012.12.022.

[39] Zydan. Shr. (2008). Sykwlwjyh Altfl Alasm, Alqahrh. Dar Eytrak. 